\title{
Employment Assimilation of Immigrants in The Netherlands: Dip and Catchup by Source Country
}

\author{
Aslan Zorlu' ${ }^{1}$ and Joop Hartog ${ }^{2}$ \\ ${ }^{1}$ Department of Human Geography, Faculty of Social and Behavioral Sciences, University of Amsterdam, Nieuwe Prinsengracht 130, \\ 1018 VZ Amsterdam, The Netherlands \\ ${ }^{2}$ Amsterdam School of Economics, University of Amsterdam, Roetersstraat 11, 1018 WB Amsterdam, The Netherlands
}

Correspondence should be addressed to Aslan Zorlu, a.zorlu@uva.nl

Received 7 November 2011; Revised 23 February 2012; Accepted 7 March 2012

Academic Editor: Oliver Duke-Williams

Copyright (c) 2012 A. Zorlu and J. Hartog. This is an open access article distributed under the Creative Commons Attribution License, which permits unrestricted use, distribution, and reproduction in any medium, provided the original work is properly cited.

Using two Dutch labour force surveys, we compare employment assimilation of immigrants by source country, after ranking countries by presumed social-cultural distance to The Netherlands. We test this ranking of human capital transferability on the ranking by initial performance dip at entry as an immigrant and speed of assimilation as measured by the slope on years-sincemigration. We also test the predicted association between entry gap and speed of assimilation (faster assimilation if the initial dip is larger). Both hypotheses are largely supported. Most immigrant groups never reach parity with native Dutch, neither in (un-)employment probability nor in job quality, and certainly not within 25 years after arrival.

\section{Introduction}

Europe has inherited a heterogeneous immigrant population from several stages in its recent history. In the postwar period, after accommodating migration flows following the war upheaval and the decolonisation era, large numbers of low-skilled immigrants entered the north-western European labour markets. When the long postwar boom period ended, these flows were cut off, but family formation and reunification kept entry at substantial levels. During the "90s," refugees massively knocked on the door; admission rates initially were substantial, but later this inflow was also severely restricted. Immigration of guest workers and their relatives and of refugees has left the countries in North West Europe with large populations with a disadvantaged socioeconomic position. For several decades now, governments have sought policies to integrate these immigrants (and their offspring) smoothly into society, with little visible success. The new policy interest is in acquiring high-skilled immigrants to boost the international competitive position. In the meantime, the European Union (EU) has opened up labour markets ever further; labour mobility between the old
EU countries, with labour forces of comparable qualification structure, is free, immigration from the new EU members, with sometimes quite different level and distribution of qualifications, is also completely free or will soon be so. Thus, policy attention concentrates on integrating the stock of unskilled "old" immigrant groups, on shifting from lowskilled to high-skilled new immigrants (who presumably assimilate much more easily and smoothly than the old unskilled groups) and on coping with immigrants from the new EU members.

Immigration to The Netherlands followed the common European sequence. Asian decolonisation generated two major immigration waves from Indonesia, 1949-1951 and 1952-1957, and a relatively smaller immigration in the early 1960s. Decolonisation of Surinam (Dutch Guyana) led to two large immigration flows, in the year of independence (1975) and during the political upheaval of 1979-1980. Integration of Indonesian immigrants has been relatively smooth (apart from a brief period of political turmoil and violence by Moluccans in the 1970s). However, Surinamese migrants have still a disadvantaged position and so have immigrants from the Dutch Antilles, still part of the Dutch kingdom. 
The flow of "guest workers" started in the beginning of the 1960s, predominantly from Italy, Spain, Portugal, Turkey, Greece, Morocco, and Yugoslavia. Many immigrants from Italy, Spain, Portugal, and Greece have returned home as these countries have integrated in the European Union, while immigration from Turkey and Morocco kept growing due to the inflow of spouses, children, and brides of these predominantly male workers despite increasingly tighter immigration policy.

In the end, Surinamese, Antilleans, Turks, and Moroccans have become the largest immigrant groups in the Netherlands. Immigrants from (former) colonies (Surinamese; Antilleans) are familiar with Dutch society and often speak the language, while Turks and Moroccans have a different religious and cultural background and often have very poor command of the Dutch language, new and old immigrants are now required to learn Dutch.

During the 1990s, immigration flows were dominated by asylum migrants from among inter alia former Yugoslavia and Soviet Union, Iran, Iraq, Afghanistan, and China. Further tightening of immigration policies in the beginning of the 2000s has hindered asylum migration as well as family migration from Turkey and Morocco substantially. At the same time, the extension of the European Union with eastern European countries has generated a legal ground for immigration from these countries even though this immigration is not yet completely free and subject to controls according to the perceived need for immigrant labour.

In addition to the immigrant population from nonwestern countries, The Netherlands hosts a large number of immigrants from the European Union countries and from other developed countries like the United States, Canada, Australia, and Japan. All these immigrants are categorised as Western immigrants. They enter The Netherlands as labour migrants and perform even slightly better than natives in the labour market. The stock of these immigrants does not change very much, although the flows are rather sensitive to business cycles.

Economic studies often use wages as the labour market outcome to analyse assimilation of immigrants [1, $2]$. However, wages are likely only a limited measure of labour market outcomes in European labour markets, where, unemployment rates are structurally high and participation rates are low, particularly for immigrants. In the Netherlands, the dramatically low participation rates of immigrants is reason for policy concern. Employment assimilation is seen as a key aspect of labour market assimilation and cannot be ignored. This study examines employment and occupational assimilation of male and female migrants in the Netherlands. By studying employment assimilation, we aim to provide evidence on the share of the immigrant population that is successful in securing paid work. By studying unemployment, we provide evidence on assimilation measured as the difficulty of the outsider who is looking for a job without success. Thus, employment and unemployment measure different dimensions of assimilation: generating an income from employment and not having an employment contract if one would want one. Our data include an internationally comparable measure of participation and unemployment. Since in less flexible European labour markets, access to occupations is often formally regulated, and many immigrants cannot fully exploit their original skills and crafts, this study also pays attention to the type of occupations that immigrants hold ${ }^{1}$.

We use the dip-and catch-up model as our basic frame of analysis: immigrants start out at a performance gap relative to similarly qualified natives, but they may catch up as the length of their stay in the host country increases. This makes years-since-migration our variable to measure the path of assimilation. We present detailed pictures of the labour market position of six immigrant groups, and we structure the analysis of their relative position by an $a$ priori ranking of sociocultural distance to the Netherlands of immigrant source countries and by focussing on the relationship between initial gaps at entry and speed of assimilation over time. In the next section, we outline our plan of analysis. Section 3 presents the data. Section 4 discusses the limits of cross-section data. Section 5 analyses employment and unemployment probabilities. Section 6 analyses occupational structures. Section 7 focuses on the effect of socioeconomic distance and the relationship between initial gap and later catching up. Section 8 concludes.

\section{Plan of Analysis}

One might define successful integration or assimilation ${ }^{2}$ as the situation where an ethnic group that is observationally equivalent to native-born citizens in personal characteristics is also observationally equivalent in socioeconomic outcomes (employment rate, earnings, and job quality). A useful tool to study this is the dip and catchup model: immigrants enter at a disadvantage relative to comparable natives because they lack host country specific skills, but they will catch up because of their strong incentives to invest in these skills. Integration takes time, and immigrants may integrate only gradually. The Dip and Catch-up model has been developed and mostly applied in the United States, almost exclusively focused on earnings of male immigrants $[1,3-$ $5]$. We will extend the range of application and also estimate the assimilation pattern of immigrant women ${ }^{3}$ and we will go beyond wages. Looking only at wages implicitly assumes that immigrant labour market assimilation takes place predominantly through wages and access to employment is self-evident. Such an assumption may, perhaps, apply to the US labour market, but it is less relevant for northern and western European countries with a less flexible labour market and a generous welfare system.

In European labour markets, labour market participation is an important issue in immigrant assimilation because especially immigrants from nonwestern countries have dramatically low participation and high unemployment rates. A small number of studies show that nonwestern immigrants experience an initial employment disadvantage, and that the assimilation pattern of immigrants varies by the country of 
origin [6-9]. The low activity rate and high welfare benefit rate of immigrants is seen as a significant redistribution mechanism and also as a source of poor integration of migrants in social, cultural, and political domains of society although a reverse causality cannot be excluded. Therefore, immigrants' labour market performance is at the heart of public debate in the Netherlands, like in other European countries.

Labour market disadvantage of immigrants systematically extends beyond employment status. It appears also within the segment of employment. A concentration of immigrants in particular types of employment, occupations, and sectors has consequences for the quality of their jobs, earnings, employability, and correspondingly career prospects. However, little is known about the assimilation pattern of immigrants by job type, and we will contribute new evidence on this issue.

The dataset we use, the Labour Force Survey (LFS) 2004 and 2005, contains no information on wages and household income but does include detailed information on characteristics of employment. Therefore, this study estimates reduced form probabilities of employment and unemployment: without wage information, labour supply behaviour cannot be modelled structurally. Occupational assimilation is approximated by ceteris paribus immigrant mobility into better jobs. The job quality is assessed by the Erikson-Goldthorpe-Portocarero social class scheme (EGP), which has been derived from a number of factors like income, economic security, likelihood of promotion, position in production relations, power relations in the production process, and the degree of autonomy. This paper is the first in the Netherlands studying employment assimilation of migrants over time.

Using cross-section data admittedly has a methodological drawback because the analysis cannot properly deal with possible changes in quality of immigration cohorts, selective return migration, and variation in economic conditions. The use of cross-section data for The Netherlands is inevitable, as we have no suitable panel data ${ }^{4}$. But we will argue in the next section that country of origin is a good predictor of immigrant quality, and that variation in unobserved quality between surviving cohorts from a given source country may be modest; while empirically not much is known about quality variation among (surviving) cohorts, we argue that if anything, we may overestimate the effect of years-sincemigration on labour market outcome.

Heterogeneity of the immigrant population by source country may give rise to different patterns of assimilation. Duleep and Regets [10] formulated specific hypotheses on the impact of skill transferability, which we may assume to be related to sociocultural distance. The general underlying hypothesis is that low-skill transferability implies a larger initial performance gap and faster catchup. Several implications follow. The performance difference between highand low-skill transferability should diminish over time. If initially nontransferable human capital is useful in producing new human capital, education will do more to encourage investment among low-skill transferability immigrants than among high-skill transferability immigrants. We will check to what extent these predictions can be observed in our data.

\section{Data and Descriptive Statistics}

This study uses Labour Force Survey (LFS) data from Statistics Netherlands. The survey includes internationally comparable measurements of employment, occupations, and education. An immigrant is defined as a foreign born individual from non-Dutch parents. Second generation immigrant refers to those who were born in the Netherlands from foreign parent(s) and those who entered the Netherlands before they were seven years old. To retain more observations on immigrants, we pool LFSs from 2004 and 2005; we restrict the sample to people aged 25 to 64 years who are not in fulltime education. LFS contains information about education in addition to a large number of other variables. However, no distinction is made between education acquired in the home country or in the Netherlands. This raises some concern about measurement error when foreign education has been translated to the standard education classification in the Netherlands: registration officers may apply their perception on the usefulness of source country education on the Dutch labour market (see [11]).

Considering similarities in starting conditions in the labour market, immigrants are clustered into 6 groups. The first group (TurkMoroc) contains Turkish and Moroccan immigrants whose labour market positions are very similar. Immigrants from Dutch Antilles and the former colony Suriname are pooled into the second category (Caribbean). The third group covers eastern European immigrants (EastEur). The fourth group (Refugees) contains Iranian, Iraqi and Afghani immigrants who have often significantly contributed to refugee flows into the Netherlands (note that this classification is based on source country, not on individual refugee status). Other nonwestern migrants are aggregated into the fifth group $(N W)$ that also includes immigrants from some other, less important refugee countries. Immigrants from western countries (OECD excluding Turkey) are clustered into the category Western.

Differences in labour market positions are likely due to differences in human capital endowments and demographic characteristics of the groups. Our data allow us to measure a number of these characteristics. But many relevant characteristics have not been measured, and if measured, are subject to unobserved qualitative differences. Such differences will have a country-specific component that determines skill transferability. One would expect western immigrants to perform best: they are from developed countries with similar culture as The Netherlands and as the income levels are also comparable, one would expect the immigrants to be positively selected. Next in line one would expect the Caribbeans: they are familiar with the Dutch language, and the school system is essentially Dutch. East Europeans may be ranked third: quality of education is often high and 
TABLE 1: Mean values of variables by gender and origin, 25-64.

\begin{tabular}{|c|c|c|c|c|c|c|c|c|c|c|c|c|c|c|}
\hline & \multicolumn{7}{|c|}{ Men } & \multicolumn{7}{|c|}{ Women } \\
\hline & Native & TurMor & Car & East & Ref & NW & West & Native & TurMor & Car & East & Ref & NW & West \\
\hline Employed & 0.85 & 0.68 & 0.78 & 0.73 & 0.49 & 0.72 & 0.80 & 0.67 & 0.35 & 0.65 & 0.55 & 0.22 & 0.50 & 0.65 \\
\hline Unemployed & 0.04 & 0.18 & 0.16 & 0.14 & 0.29 & 0.18 & 0.06 & 0.05 & 0.10 & 0.13 & 0.14 & 0.14 & 0.12 & 0.06 \\
\hline EGP & 1.78 & 2.41 & 2.01 & 2.12 & 2.37 & 2.16 & 1.73 & 1.90 & 2.36 & 2.05 & 2.14 & 1.98 & 2.28 & 1.89 \\
\hline Age & 44.79 & 38.86 & 41.37 & 42.77 & 40.48 & 40.71 & 46.00 & 44.64 & 37.08 & 41.23 & 41.04 & 38.76 & 39.58 & 45.36 \\
\hline Second gen & & 0.15 & 0.28 & 0.24 & 0.01 & 0.11 & 0.74 & & 0.19 & 0.24 & 0.15 & 0.01 & 0.10 & 0.70 \\
\hline YSM (Imm) & & 18.78 & 21.14 & 13.1 & 8.96 & 14.5 & 23.2 & & 18.01 & 20.6 & 12.1 & 8.29 & 13.2 & 21.6 \\
\hline Education & 13.43 & 10.77 & 12.52 & 13.62 & 13.37 & 12.63 & 13.63 & 12.85 & 9.56 & 12.26 & 13.43 & 11.92 & 12.06 & 13.10 \\
\hline Married & 0.56 & 0.56 & 0.53 & 0.55 & 0.58 & 0.57 & 0.54 & 0.53 & 0.51 & 0.44 & 0.51 & 0.52 & 0.49 & 0.50 \\
\hline $\begin{array}{l}1 \text { Child } \\
0-5 \text { yrs }\end{array}$ & 0.12 & 0.30 & 0.16 & 0.17 & 0.21 & 0.21 & 0.12 & 0.12 & 0.30 & 0.17 & 0.19 & 0.27 & 0.23 & 0.13 \\
\hline $\begin{array}{l}\text { More child } \\
0-5 \text { yrs }\end{array}$ & 0.08 & 0.14 & 0.07 & 0.07 & 0.09 & 0.12 & 0.06 & 0.08 & 0.14 & 0.07 & 0.05 & 0.09 & 0.10 & 0.07 \\
\hline $\begin{array}{l}\text { Child } \\
6-11 \text { yrs }\end{array}$ & 0.19 & 0.38 & 0.18 & 0.20 & 0.26 & 0.25 & 0.17 & 0.20 & 0.44 & 0.26 & 0.22 & 0.38 & 0.30 & 0.19 \\
\hline Full-time & 0.76 & 0.60 & 0.70 & 0.66 & 0.39 & 0.62 & 0.71 & 0.16 & 0.13 & 0.28 & 0.20 & 0.07 & 0.21 & 0.19 \\
\hline Hours 24-32 & 0.06 & 0.04 & 0.06 & 0.05 & 0.04 & 0.07 & 0.06 & 0.20 & 0.09 & 0.22 & 0.17 & 0.10 & 0.13 & 0.20 \\
\hline $\begin{array}{l}\text { Naturalised } \\
(\mathrm{Imm})\end{array}$ & & 0.17 & 0.65 & 0.12 & 0.07 & 0.32 & 0.09 & & 0.14 & 0.66 & 0.16 & 0.05 & 0.30 & 0.12 \\
\hline$N$ & 61333 & 1728 & 1160 & 522 & 410 & 971 & 5333 & 62136 & 1716 & 1549 & 851 & 285 & 1278 & 5829 \\
\hline
\end{tabular}

as Europeans they have relatively short cultural distance. Ranking Turks/Moroccans, refugees, and nonwestern immigrants is more difficult: in all cases, there is a substantial cultural difference, and the nature and quality of education are each quite different from Dutch education. One might argue that in case of refugees, the migration decision is not primarily based on economic matching and skill transferability may therefore be expected to be quite low. Then, our predicted ranking by economic success will be Western, Caribbean, East European, Turks/Moroccans/Non-western, Refugees. Refugees, however, may be a more heterogeneous group than the other categories and its ranking is therefore somewhat more speculative. While refugees obviously are not motivated to migrate by labour market conditions, among the other source country groups there are also many with different motivations: study and family considerations are also important. In particular for Turks and Moroccans, the early dominance of the labour market motive has been replaced by family reunification and formation.

Table 1 presents mean values of dependent variables (employment and unemployment) and covariates for natives and the immigrant subsamples. It is immediately apparent that the demographic and educational characteristics of western immigrants are similar to natives. Note, in Table 1, that the average education level of immigrants from western and east European countries is even higher than that of natives. Other immigrant groups have a younger age structure and their educational distribution is characterized by significant intergroup differences. Turks/Moroccans have the lowest education level with a high concentration in the lowest category, while refugee immigrants have a bipolar distribution with relatively large concentrations in the lowest and highest categories.

Immigrants, but especially nonwestern immigrants are relatively young and more often lower educated on average. They have more often children aged below 12 years. Interestingly, the share of immigrants from Western, NW, and Refugee countries having a university education is higher than for natives. As indicated by the mean values of years since migration (YSM), western immigrants have the highest, indicating that western immigration has a long tradition. Refugees are the most recent immigrants; almost all refugees in our data arrived after 1990.

Employment probabilities of the immigrant groups are in general lower than for natives while their unemployment and inactivity rates are relatively high. Taking employment probability as a measure of economic success, the ranking in this crude unstandardised outcome already conforms to our expectation, both for men and for women. For unemployment, the ranking also conforms, while for women, only unemployment among Turks, Moroccans and other nonwestern immigrants is out of step.

\section{The Limitations of Cross-Section Data}

Using cross-section data is potentially subject to three methodological drawbacks: possible changes in quality of immigration cohorts, selective return migration and changes 


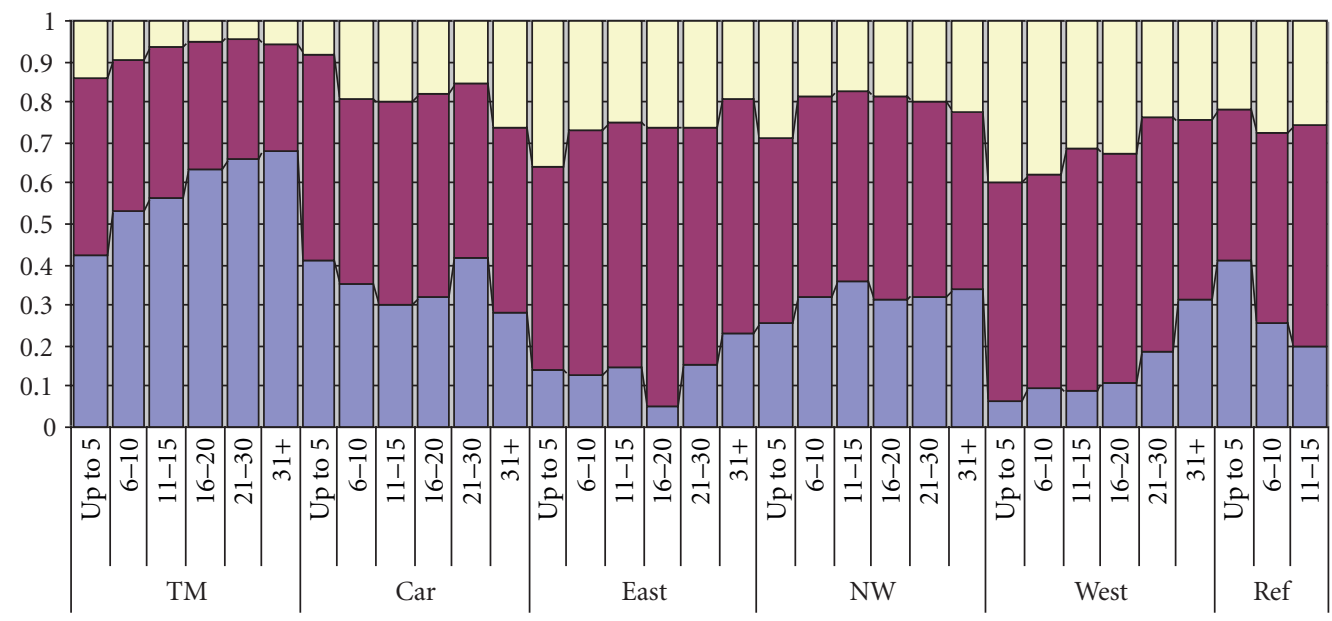

(YSM)

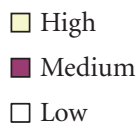

FIGURE 1: Educational distribution by YSM and origin.

in economic conditions that have lasting effects. We use cross-section data simply because longitudinal data for The Netherlands have no information on education. We will now discuss the possible consequences.

Change in unobserved immigrant quality over time may give misleading results: if measured from cross-section observations, changes in performance with time elapsed since migration may reflect different qualities of entering immigrant cohorts rather than effects of acquiring more destination-specific human capital. We doubt that this is a big issue in our case. There are large differences, no doubt, in unobserved quality between immigrants from different source countries, but we control for source countries ${ }^{5}$. Changes in immigrant cohort quality over time, for a given source country, can never be fully documented. But education is probably the most powerful indicator of quality, and this is observed in our data. In Figure 1, we show educational compositions for successive cohorts. The changes are modest for Caribbean, East European, and nonwestern immigrants. Among western immigrants the level of education gradually increases, among refugees there is an increase in the share of low educated, among Turks and Moroccans there is a steady increase in level of education. We see no good reason to assume systematic change in unobserved quality for immigrants from western countries, from Caribbean countries, nor from nonwestern countries. East European immigrants are mostly from Poland, and there is no indication that their qualities have changed over time. Refugees do not select themselves on basis of labour market qualities, and we expect no big changes over time. For Turks and Moroccans, unobserved quality may have changed over time, as the earliest guest workers, in the 1960s, were recruited from the very lowest segments of the labour force and many could barely read or write (as reflected in our education data). Later immigration from these countries is dominated by family formation or reunification, and we do not see much reason to fear systematic quality change here. Moreover, many of the relevant unobserved qualities (ambition, drive, and perseverance) no doubt correlate with education, and this will restrain any quality bias in the estimated effect of YSM (but, as usual, bias the coefficient of education).

Selective return migration may also bias the coefficient of YSM as a causal measure of economic success. If the effect of exposure per se is zero, the estimated profile will only show the differences between immigrants still around after $t$ years and after $t+1$ years. With negatively selected emigration, the profile will slope upwards (more successful immigrants stay), with positively selected emigration the profile will slope downwards (the less successful stay).

We know that return migration is substantial [12] and varies markedly between categories [9, 13, 14]. For the Netherlands, Zorlu et al. [9] document that between 1995 and 2001, 658000 persons born abroad immigrated, and that 142000 , or $22 \%$, of them had left again by 2001 . Among labour migrants (using entry cohort 1997), 62\% had left within five years, while among refugees only $13 \%$ had left. Among immigrants motivated by family re-unification, 19\% has left within five years, while this is $16 \%$ for immigrants motivated by family formation.

Bijwaard [15] estimates the long-run probability of ending up in The Netherlands, by motive and country of origin. For an unmarried male immigrant from an EU or EFTA country, the probabilities are $51 \%$ for labour migrants, $35 \%$ for family reunion, and $74 \%$ for family formation (Bijwaard excludes refugees). The percentages are 
substantially higher for married men and for women. By country of origin, variation is modest for family formation (mostly between 85 and 95\%) and larger for labour migrants (roughly between 57 and 89\%) and also larger for family reunion (roughly between 37 and $74 \%$ ).

Research on selectivity in return migration is not abundant, and a standard pattern has not been established. Edin et al. [13] find that the least successful immigrants leave, with attachment to the labour market in the first five years a better predictor of emigration than earnings. The bias in estimated assimilation from ignoring emigration is much larger for economic immigrants than for political migrants, much larger (in Sweden) for Nordic and OECD immigrants than for non-OECD immigrants, simply on account of differences in the intensity of emigration. Bijwaard et al. [16] find evidence on selectivity of recent labour migrants in the Netherlands: unemployment spells shorten duration of immigration, reemployment spells delay returns, with different intensities by ethnicity. Constant and Massey [17] cite some European studies that suggest negative selection of return migration; in their analysis of the first 14 years of the German SOEP panel, they find no evidence of selectivity bias when estimating earnings functions corrected for selective emigration, but they do report that return migration is sensitive to employment: immigrants without a job are more likely to leave. They also report evidence of negative selection with respect to occupational prestige. Rooth and Saarela [18] found that return migration for Finns in Sweden is not selective in unobserved skills relevant for earnings.

If anything, we may expect from the scant literature a tendency towards negative selection (the least successful will leave), and that selective return may be more prominent among labour migrants than among family migrants and refugees. The literature gives no explicit analytic results on selectivity bias in probit models, but reasoning by analogy to the linear probability model, with the sign of the bias determined by the covariance between error and regressor, we should anticipate a possible upward bias in our coefficient on YSM, from a potentially positive correlation between YSM and unobserved quality in the error term. Our estimate would then give an upper bound.

Cross-section analysis may also provide biased estimates when immigrants and natives are asymmetrically influenced by business cycles. Chiswick et al. [2] note the role of high unemployment at the time of entry and path dependence in the following years. Longva and Raaum [19] show that labour market outcomes for immigrants are more sensitive to a rise in unemployment than for natives. Aggregate unemployment fluctuated strongly over the long arrival period of our immigrants. After the very low levels during the 1960s (below 1 percent), it grew to levels above 5 percent in 1982, with a peak of 8.3 percent in 1983; since 1998 it is again below 5 percent. To the extent that unemployment at arrival leaves permanent effects, as lasting differences between arrival cohorts, one should expect a $\mathrm{u}$-shaped bias in the estimated effect of years since arrival: compared to the earliest arrivals in the 1960s, there would be an increasing and later decreasing upward bias. This would mostly affect groups with substantial shares of long durations, such as Turks/Moroccans and Caribbeans; refugees arrived mostly after 1990 and experienced a much flatter unemployment history. However, the argument is more complicated than this, and there may be opposing effects as well. Immigration drops when unemployment is high and potentially, selectivity increases towards better qualified immigrants. Moreover, the older immigrants, initially employed in manufacturing, suffered its demise and may have lost their early advantage. It is not easy to formulate a reliable anticipation on the direction and magnitude of the bias. Perhaps it is wise to assume a mild upward bias form this source in the estimated coefficient of YSM.

We conclude that we should be aware of potential upward bias in estimated effects of YSM, implying that our estimates will give an upper bound for a true causal effect.

\section{Employment and Unemployment}

Upon arrival in the Netherlands, immigrants' opportunities for employment will differ according to source country and personal characteristics. We expect in particular differences between immigrants from western and from nonwestern countries, for two main reasons. The first one refers to different immigration policies for these groups. Western immigrants do not face any legal restriction and they enter usually as a labour migrant with a job secured before arrival; nonwestern immigrants may enter only on humanitarian grounds, as a family or asylum migrant. Correspondingly, nonwestern immigrants have often no permission for work immediately upon arrival. They need some time to get full access to the labour market. The second argument for the smooth transition of western immigrants to the labour market refers to a high degree of skill transferability from their home country and to selectivity of immigrants. Skills of nonwestern migrants may not be easily transferred, and immigrants entering on humanitarian reasons may lack sufficient measured and unobserved qualifications.

To model the progress of assimilation, we assume that the probability of employment, as employee or self-employed, $y$, is captured by the following regression equation:

$$
\begin{aligned}
y= & \alpha+\beta_{1} A+\beta_{2} A^{2}+\beta_{3} \mathrm{SG}+\beta_{4} \mathrm{YSM} \\
& +\beta_{5} \mathrm{YSM}^{2}+\sum_{j=1}^{6} \beta_{m j} M_{j}+\beta_{6} \mathrm{Edu} \\
& +\sum_{j=1}^{6} \beta_{m y j}\left(\mathrm{YSM} * M_{j}\right)+\beta_{7} X+\varepsilon,
\end{aligned}
$$

where $A$ is age (with identical effect for natives and immigrants), SG is a dummy variable for the second generation, YSM is years since migration, and $M$ is the set of indicator variables for 6 immigrant groups. By construction, YSM $=0$ for natives and for the second generation. Edu is education 
(measured as seven categories), $X$ is other controls (marital status, and the number of children aged between 0 to 11 years). The dependent $y$ equals 1 if employed, 0 if unemployed or inactive.

Equation (1) has been fitted by standard probit models for the subsamples of men and women separately, since participation behaviour of women is different from men. We present four models to facilitate understanding the role of education, varying assimilation patterns for immigrant groups and family status ${ }^{6}$.

Since migrants are more likely unemployed than natives, we also estimate unemployment probabilities by gender similar to the estimation procedure of employment probabilities to provide a more complete picture of the labour market. Unemployment probability $U$ is defined as:

$U=1$, if individual is a labour market participant and unemployed;

$U=0$, if individual is employed.

Unemployment probabilities are separately estimated for men and women using (1).

Age, age at entry, and YSM are correlated with each other (and linearly related by definition). Effects of these variables cannot be separated in a cross-sectional setting. Using these variables simultaneously in regression analysis is in fact an overspecification of the assimilation process. Therefore, we do not include all these variables simultaneously in regression models. Instead, we include age and YSM, setting YSM at zero for nonimmigrants. Immigrants who arrived before age seven are considered to be second generation. Excluding age at entry may bias YSM coefficients because age at migration may have its own effect on assimilation. In particular, age at migration is considered to be an important determinant of schooling outcomes of immigrants since compulsory education is directly related to age. Immigrants who arrived at school-going age (after 6; before 16) acquired at least part of their education in the host country. These immigrants might therefore have accumulated more country-specific capital than late arrivals due to formal schooling. If this reasoning is true, coefficients for YSM will indicate an overestimation of employment assimilation. In our data, we have relatively few immigrants who arrived before a mature age which lowers the risk of overestimation.

5.1. Estimates of Employment Probabilities. In (1), the coefficients of YSM and YSM $^{2}$ measure how the nativeimmigrant employment gap diminishes as immigrants gain country specific experience, if no systematic changes have occurred in unobserved employment potential $\varepsilon$ of successive immigration cohorts. Since YSM captures the assimilation effect over time, the indicator variables for immigrant groups (M) reflect the initial employment gap of immigrants in the year of arrival relative to comparable natives. We test for different assimilation profiles by allowing interaction terms between YSM and M. Table 2 shows the estimates of employment probabilities for men and women separately. To facilitate interpretation, also marginal effects are presented; for dummy variables, this gives the percentage point difference in the employment probabilities of the dummied group and the reference category (natives). Starting from Model I, Model II adds education, Model III differentiates assimilation profiles, and Model IV adds family background, marital status, and urbanisation. Adding seven education dummies to the regression (moving from Model I to Model II) does not change the marginal effect of the other variables.

The employment probability for men and women goes up with age, but at a decreasing rate. Assimilation profiles are also concave. As expected but not shown, we find that individuals with a higher education level are more likely to be employed. Immigrants' assimilation pattern can be affected differently by their education level already accomplished upon arrival and by later investments, but unfortunately, as in most studies, our data do not allow the distinction between education acquired abroad and education acquired domestically. The data collector possibly translated foreign education into equivalent domestic scales, but we have no information on this. The coefficients for the country of origin dummies give the initial employment gap of immigrants upon arrival. The entry gaps have the same ranking for men and for women. The gap is largest for refugees, the next group is non-western, Turks/Moroccans, East Europeans, and Caribbeans, with modest differences between them and the smallest gap, not surprisingly, is for western immigrants. This ranking is perfectly in line with the expectation we derived from the Duleep-Regets hypothesis. Second generation immigrants do substantially better than first generation immigrants, but for men, the positive generation gap never wipes out the negative entry gap, implying that even second generation immigrants have a weaker labour market position. We have estimated second generation effects separately by origin country and found that the performance of the second generation Eastern European and other nonwestern immigrants (both men and women) is significantly better than for other origin groups (models with such interaction terms are not shown here). However, allowing the second generation gap to vary by source country, we still find that for men no entry gap is wiped out by the second generation gap; for women, it is only wiped out for western immigrants. Hence, for essentially all source countries, second generation immigrants have poorer employment probabilities than native Dutch of similar qualities ${ }^{7}$.

The assimilation profile indicates that the probability of employment increases at a decreasing rate and reaches a maximum for men after 18 years $^{8}$, and 20.5 years when controlling for education level, after 27 and 30 years for women. If we allow different assimilation patterns for the migrant groups, rather than assuming a common assimilation structure, the assimilation rate is the highest for refugees who have a very high initial employment gap $^{10}$ (models III and IV). They are followed by nonwestern immigrants, immigrants from Turkey/Morocco have the 
TABLE 2: Employment probabilities, probit: coefficient, (marginal effect), and (standard error).

\begin{tabular}{|c|c|c|c|c|c|c|c|c|}
\hline & \multicolumn{4}{|c|}{ Men } & \multicolumn{4}{|c|}{ Women } \\
\hline & Mod I & Mod II & Mod III & Mod IV & Mod I & Mod II & Mod III & Mod IV \\
\hline \multirow{3}{*}{ Age } & $0.260^{* * *}$ & $0.265^{* * *}$ & $0.266^{* * *}$ & $0.261^{* * *}$ & $0.147^{* * *}$ & $0.154^{* * *}$ & $0.155^{* * *}$ & $0.159^{* * *}$ \\
\hline & {$[0.052]$} & {$[0.051]$} & {$[0.051]$} & [0.049] & {$[0.053]$} & {$[0.055]$} & {$[0.056]$} & [0.057] \\
\hline & $(0.001)$ & $(0.001)$ & $(0.001)$ & $(0.001)$ & $(0.002)$ & $(0.002)$ & $(0.002)$ & $(0.002)$ \\
\hline \multirow{3}{*}{ Age-sq } & $-0.003^{* * *}$ & $-0.004^{* * *}$ & $-0.004^{* * *}$ & $-0.003^{* * *}$ & $-0.002^{* * *}$ & $-0.002^{* * *}$ & $-0.002^{* * *}$ & $-0.002^{* * *}$ \\
\hline & {$[-0.001]$} & {$[-0.001]$} & {$[-0.001]$} & {$[-0.001]$} & {$[-0.001]$} & {$[-0.001]$} & {$[-0.001]$} & {$[-0.001]$} \\
\hline & $(0.000)$ & $(0.000)$ & $(0.000)$ & $(0.000)$ & $(0.000)$ & $(0.000)$ & $(0.000)$ & $(0.000)$ \\
\hline \multirow{3}{*}{ YSM } & $0.036^{* * *}$ & $0.041^{* * *}$ & $0.028^{* * *}$ & $0.027^{* * *}$ & $0.054^{* * *}$ & $0.060^{* * *}$ & $0.051^{* * *}$ & $0.054^{* * *}$ \\
\hline & {$[0.007]$} & {$[0.008]$} & {$[0.005]$} & {$[0.005]$} & {$[0.020]$} & {$[0.022]$} & {$[0.018]$} & {$[0.019]$} \\
\hline & $(0.001)$ & $(0.001)$ & $(0.001)$ & $(0.001)$ & $(0.002)$ & $(0.002)$ & $(0.002)$ & $(0.002)$ \\
\hline \multirow{3}{*}{ YSM-sq } & $-0.001^{* * *}$ & $-0.001^{* * *}$ & $-0.001^{* * *}$ & $-0.001^{* * *}$ & $-0.001^{* * *}$ & $-0.001^{* * *}$ & $-0.001^{* * *}$ & $-0.001^{* * *}$ \\
\hline & {$[0.000]$} & {$[0.000]$} & {$[0.000]$} & {$[0.000]$} & {$[0.000]$} & {$[0.000]$} & {$[0.000]$} & {$[0.000]$} \\
\hline & $(0.000)$ & $(0.000)$ & $(0.000)$ & $(0.000)$ & $(0.000)$ & $(0.000)$ & $(0.000)$ & $(0.000)$ \\
\hline \multirow{3}{*}{ TurkMoroc } & $-1.471^{* * *}$ & $-1.274^{* * *}$ & $-1.070^{* * *}$ & $-1.074^{* * *}$ & $-1.965^{* * *}$ & $-1.676^{* * *}$ & $-1.535^{* * *}$ & $-1.471^{* * *}$ \\
\hline & {$[-0.489]$} & {$[-0.406]$} & {$[-0.326]$} & {$[-0.325]$} & {$[-0.618]$} & {$[-0.572]$} & {$[-0.541]$} & {$[-0.527]$} \\
\hline & $(0.026)$ & $(0.027)$ & $(0.031)$ & $(0.031)$ & $(0.009)$ & $(0.013)$ & $(0.018)$ & $(0.020)$ \\
\hline \multirow{3}{*}{ Caribbean } & $-1.042^{* * *}$ & $-0.970^{* * *}$ & $-0.998^{* * *}$ & $-0.969^{* * *}$ & $-1.059^{* * *}$ & $-1.012^{* * *}$ & $-0.985^{* * *}$ & $-0.996^{* * *}$ \\
\hline & {$[-0.323]$} & {$[-0.289]$} & {$[-0.299]$} & {$[-0.286]$} & {$[-0.403]$} & {$[-0.387]$} & {$[-0.378]$} & {$[-0.382]$} \\
\hline & $(0.029)$ & $(0.029)$ & $(0.036)$ & $(0.036)$ & $(0.021)$ & $(0.022)$ & $(0.027)$ & $(0.028)$ \\
\hline \multirow{3}{*}{ East-Europ } & $-1.099^{* * *}$ & $-1.120^{* * *}$ & $-1.073^{* * *}$ & $-1.063^{* * *}$ & $-1.094^{* * *}$ & $-1.184^{* * *}$ & $-1.167^{* * *}$ & $-1.256^{* * *}$ \\
\hline & {$[-0.348]$} & {$[-0.349]$} & {$[-0.331]$} & {$[-0.325]$} & {$[-0.414]$} & {$[-0.444]$} & {$[-0.438]$} & {$[-0.466]$} \\
\hline & $(0.031)$ & $(0.032)$ & $(0.041)$ & $(0.041)$ & $(0.019)$ & $(0.019)$ & $(0.024)$ & $(0.023)$ \\
\hline \multirow{3}{*}{ RefugeeCount } & $-1.827^{* * *}$ & $-1.855^{* * *}$ & $-2.251^{* * *}$ & $-2.244^{* * *}$ & $-1.970^{* * *}$ & $-1.983^{* * *}$ & $-2.753^{* * *}$ & $-2.770^{* * *}$ \\
\hline & {$[-0.621]$} & {$[-0.626]$} & {$[-0.737]$} & {$[-0.735]$} & {$[-0.610]$} & {$[-0.616]$} & {$[-0.671]$} & {$[-0.675]$} \\
\hline & $(0.025)$ & $(0.025)$ & $(0.033)$ & $(0.034)$ & $(0.012)$ & $(0.012)$ & $(0.007)$ & $(0.007)$ \\
\hline \multirow{3}{*}{ Nonwestern } & $-1.258^{* * *}$ & $-1.203^{* * *}$ & $-1.379^{* * *}$ & $-1.364^{* * *}$ & $-1.344^{* * *}$ & $-1.299^{* * *}$ & $-1.364^{* * *}$ & $-1.376^{* * *}$ \\
\hline & {$[-0.409]$} & {$[-0.380]$} & {$[-0.450]$} & {$[-0.442]$} & {$[-0.489]$} & {$[-0.479]$} & {$[-0.497]$} & {$[-0.501]$} \\
\hline & $(0.027)$ & $(0.028)$ & $(0.034)$ & $(0.034)$ & $(0.015)$ & $(0.016)$ & $(0.019)$ & $(0.020)$ \\
\hline \multirow{3}{*}{ Western } & $-0.702^{* * *}$ & $-0.666^{* * *}$ & $-0.662^{* * *}$ & $-0.654^{* * *}$ & $-0.956^{* * *}$ & $-1.011^{* * *}$ & $-1.021^{* * *}$ & $-1.042^{* * *}$ \\
\hline & {$[-0.189]$} & {$[-0.172]$} & {$[-0.171]$} & {$[-0.167]$} & {$[-0.367]$} & {$[-0.386]$} & {$[-0.390]$} & {$[-0.397]$} \\
\hline & $(0.021)$ & $(0.021)$ & $(0.025)$ & $(0.025)$ & $(0.019)$ & $(0.019)$ & $(0.022)$ & $(0.022)$ \\
\hline \multirow{3}{*}{ Second Gen } & $0.595^{* * *}$ & $0.536^{* * *}$ & $0.527 * * *$ & $0.529 * * *$ & $1.000^{* * *}$ & $1.006^{* * *}$ & $1.004^{* * *}$ & $1.020^{* * *}$ \\
\hline & {$[0.086]$} & {$[0.076]$} & {$[0.075]$} & {$[0.075]$} & {$[0.269]$} & {$[0.265]$} & {$[0.265]$} & {$[0.266]$} \\
\hline & $(0.006)$ & $(0.007)$ & $(0.008)$ & $(0.007)$ & $(0.009)$ & $(0.009)$ & $(0.010)$ & $(0.010)$ \\
\hline \multirow{3}{*}{ Caribb*YSM } & & & $0.015^{* *}$ & $0.014^{* *}$ & & & 0.009 & $0.009^{*}$ \\
\hline & & & {$[0.003]$} & {$[0.003]$} & & & {$[0.003]$} & {$[0.003]$} \\
\hline & & & $(0.001)$ & $(0.001)$ & & & $(0.002)$ & $(0.002)$ \\
\hline \multirow{3}{*}{ EastEur*YSM } & & & 0.009 & 0.009 & & & 0.008 & 0.011 \\
\hline & & & {$[0.002]$} & {$[0.002]$} & & & {$[0.003]$} & {$[0.004]$} \\
\hline & & & $(0.001)$ & $(0.001)$ & & & $(0.002)$ & $(0.002)$ \\
\hline \multirow{3}{*}{ Refug*YSM } & & & $0.058^{* * *}$ & $0.058^{* * *}$ & & & $0.093^{* * *}$ & $0.094^{* * *}$ \\
\hline & & & {$[0.011]$} & {$[0.011]$} & & & {$[0.033]$} & {$[0.033]$} \\
\hline & & & $(0.003)$ & $(0.003)$ & & & $(0.007)$ & $(0.007)$ \\
\hline \multirow{3}{*}{ Non-west*YSM } & & & $0.027^{* * *}$ & $0.026^{* * *}$ & & & $0.015^{* *}$ & $0.016^{* *}$ \\
\hline & & & {$[0.005]$} & {$[0.005]$} & & & {$[0.005]$} & {$[0.006]$} \\
\hline & & & $(0.001)$ & $(0.001)$ & & & $(0.002)$ & $(0.002)$ \\
\hline \multirow{3}{*}{ West*YSM } & & & $0.013^{* * *}$ & $0.013^{* *}$ & & & $0.012^{* *}$ & $0.013^{* * *}$ \\
\hline & & & {$[0.003]$} & {$[0.002]$} & & & {$[0.004]$} & {$[0.005]$} \\
\hline & & & $(0.001)$ & $(0.001)$ & & & $(0.001)$ & $(0.001)$ \\
\hline Log likelihood & -24482 & -23608 & -23589 & -23519 & -40499 & -38442 & -38426 & -37633 \\
\hline Pseudo R-sq & 0.23 & 0.25 & 0.25 & 0.26 & 0.14 & 0.19 & 0.19 & 0.20 \\
\hline$N$ & 71445 & 71445 & 71445 & 71445 & 73644 & 73644 & 73644 & 73644 \\
\hline
\end{tabular}

$P<.05 ; * * P<.01 ; * * * P<.001$.

Models II and III also include dummies for 7 categories of educational achievement. Model IV additionally include 3 dummy variables for the presence of children below 11 years, controls for marital status, the degree of urbanisation, and for naturalisation of immigrants. 
lowest assimilation rate. In general, immigrant women start with a larger employment gap, but their assimilation rate is greater than for immigrant men. Adding additional controls for family background, marital status and urbanisation barely affects the coefficients of other variables: both for men and women the differences are negligible. In the next section, we will further focus on assimilation patterns.

5.2. Simulating Assimilation Patterns. Employment assimilation patterns for migrant men and women are simulated with the parameter estimates from (1). We put variables other than YSM at their sample means and choose three levels of age (Figure 2). We keep age constant for both natives and immigrants, and thus the curves give the pure effect of catching up on the gap that exists at a given age during years since migration. As the duration of residence is less than 15 years for most refugees, we have not extrapolated beyond 15 years for this group. Age and hence age at entry has an impact on the patterns of assimilation, as the model is nonlinear and employment probabilities are limited to the $0-1$ interval. The effects are parabolic, reflecting the parabolic effect of age at immigration: immigrants arriving at age 35 start at higher employment probability than immigrants arriving at age 25 , but with entry at age 45 , the employment probably appears to have fallen. There is a tendency to convergence, in the sense that the slope of the curve is higher for groups with larger gap at entry, as predicted by Duleep and Regets [10] (we will consider the relationship between initial gap and speed of catching up in more detail below). Men who enter at age 25 never fully close the gap, but some immigrant groups entering at age 35 do quite well. Western and Caribbean men reach up to parity with native men. Turkish and Moroccan men always remain behind and in fact loose more ground after 15 years. Immigrants from refugee countries have a striking speed of assimilation.

The profiles for women show similar ranking by origin country as for men, but the differences between the groups are larger. Caribbean, East-European and nonwestern women do quite well, Turkish and Moroccan women have much lower employment probabilities throughout and remain far from parity with natives. Female refugees also catch up at an amazing speed.

5.3. Estimates of Unemployment Probabilities. Table 3 displays native-immigrant unemployment differences and the impact of YSM on unemployment probabilities. Again, the differences between specifications are fairly modest. The unemployment rates for male nonwestern immigrants upon arrival are 20 to 30 percentage points higher than for natives. For women, these differences are no more than 8 to 15 percentage points, reflecting their much higher nonparticipation rates. The effect of arrival at higher age is positive at diminishing rate. Second generation immigrants also have higher unemployment, as the second generation dummy does not surpass the origin country dummies. Allowing the second generation effect to differ by origin country, we find that the immigrant disadvantage is only wiped out for the East European second generation; in all other cases we find that even second generation immigrants do worse than native born Dutch of similar observed quality. Adding some controls in specification IV (family situation, urbanisation) has little effect on other coefficients. The ranking by region of origin indicates three levels: the highest unemployment gap is for refugees, the lowest for western immigrants, the other countries are in between at fairly similar levels. The ranking for women is rather similar but at much smaller differences; for female refugees, the initial unemployment gap is replaced by an increasing gap over time. To allow differences for the second generation across the origin countries, we interacted the origin country fixed effects with the dummy for the second generation (models with these interactions not shown here). The interaction terms indicate much larger unemployment probabilities for the second generation Turkish and Moroccan men and women as well as second generation women from Eastern Europe and nonwestern countries, relative to the second generation western immigrants.

5.4. Simulations. In Figure 3 below, we graph the probability of unemployment in function of years since migration for an average immigrant: all other variables are set at their sample means for the relevant origin group. Again we see large differences between origin groups, with refugees doing worst, and Turks/Moroccans doing remarkably well. The latter effect may be due to better alternatives: nonparticipation, disability benefit. Men do not reach parity with natives, some women immigrant groups do (Caribbeans and Turks/Moroccans). Very remarkable is the difference in slopes of the profiles. Among men, East-Europeans and western men have unemployment rates increasing with years since migration, among women it is refugees and western immigrants that have this deviant pattern.

\section{Occupational Structure}

Immigrants' disadvantage is not limited to low labour market participation and high unemployment. It has been widely documented that the quality of jobs occupied by immigrants is usually relatively low. Since no direct measurement of job quality is available, and no information on wages is included in the LFS, the quality of jobs will be approximated by the Erikson, Goldthorpe, and Portocarero (EGP) social class scheme, which is regularly used by sociologists [20]. The EGP reflects various dimensions of job quality, like wages, skill requirements, employment status, power relations in production process, routines of tasks, promotion possibilities and career prospects. To assess the relative position of immigrants in occupational classes, we reorganise the original eleven categories of the EGP into three categories, referred to as (1) service class (professionals and managerial jobs), (2) intermediate jobs and (3) working class (routine nonmanual and semi- and unskilled manual jobs). We compress to 3 
TABle 3: Unemployment probabilities, probit: Coefficient, (marginal effect), and (standard error).

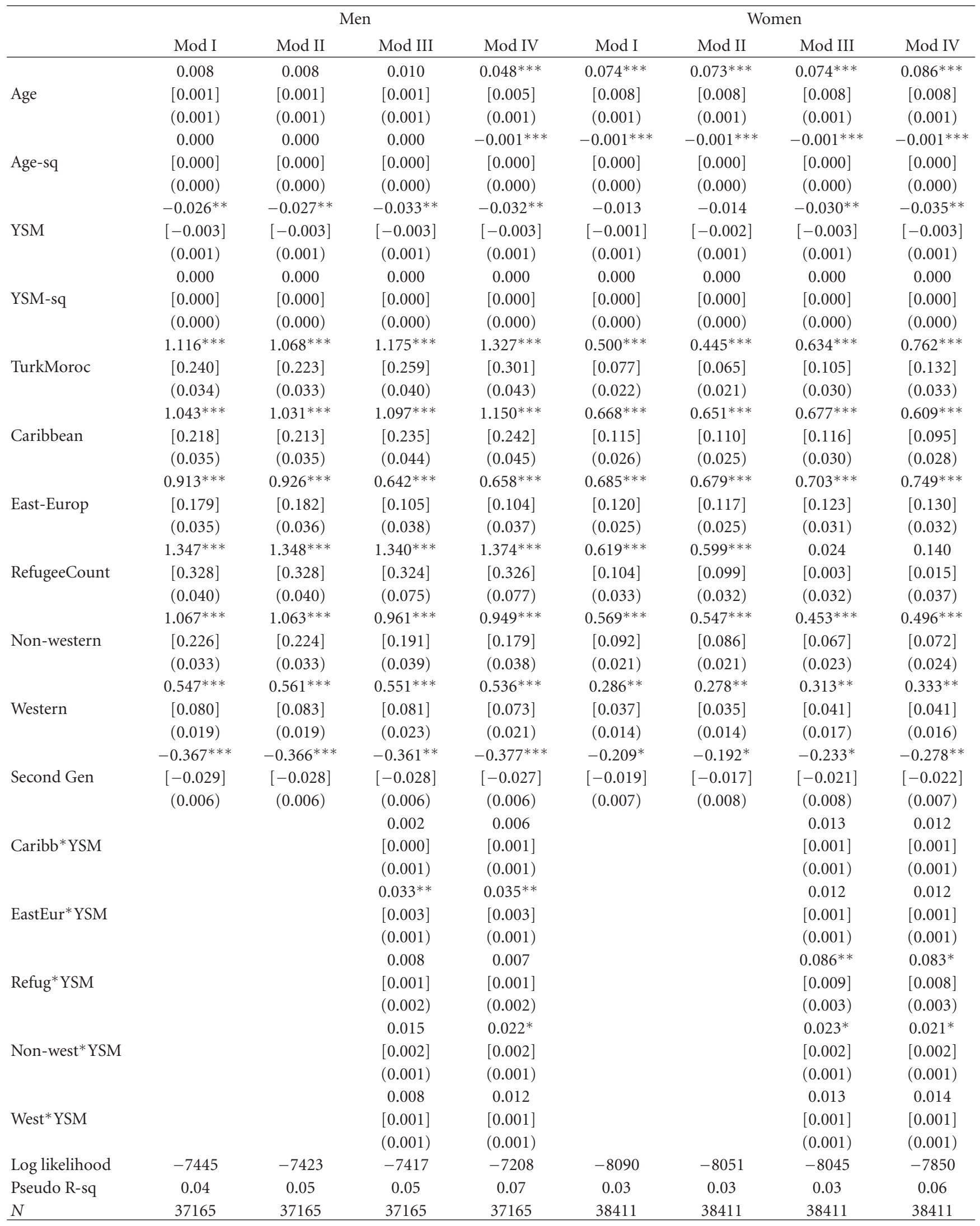

$P<.05 ; * * P<.01 ; * * * P<.001$.

Models II and III also include dummies for 7 categories of educational achievement. Model IV additionally includes 3 dummy variables for the presence of children below 11 years and controls for marital status, the degree of urbanisation, and for naturalisation of immigrants. 


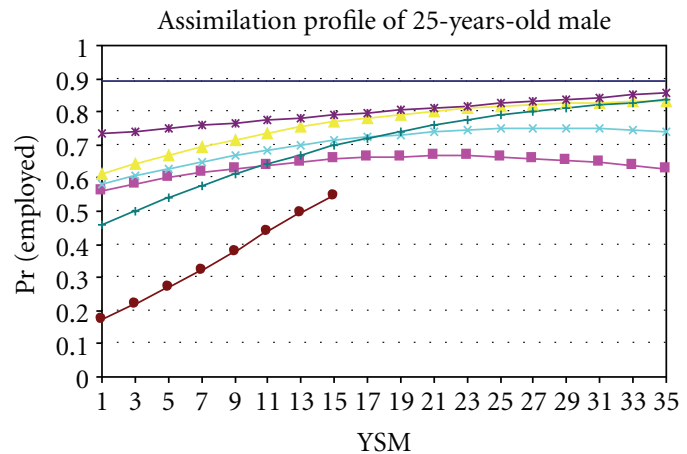

(a)

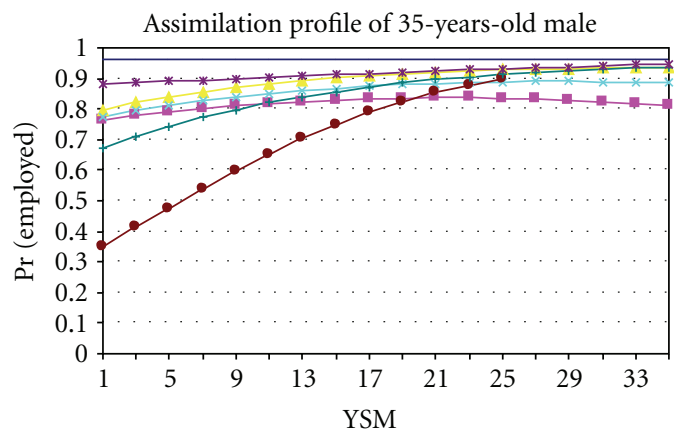

(c)

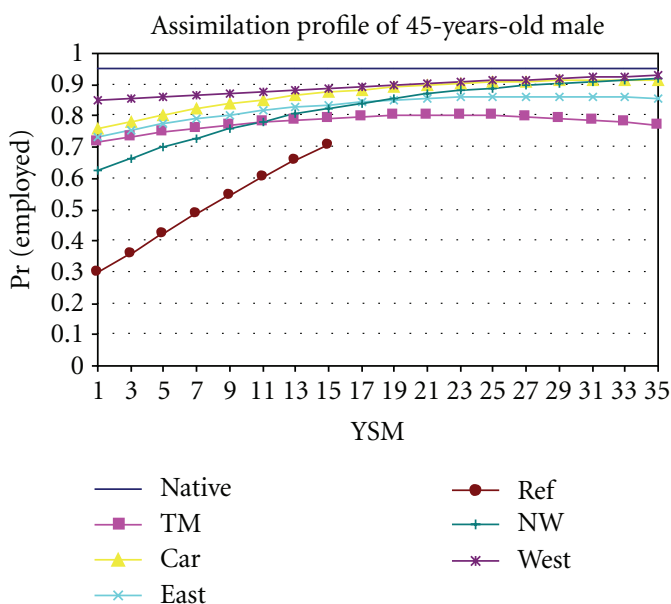

(e)

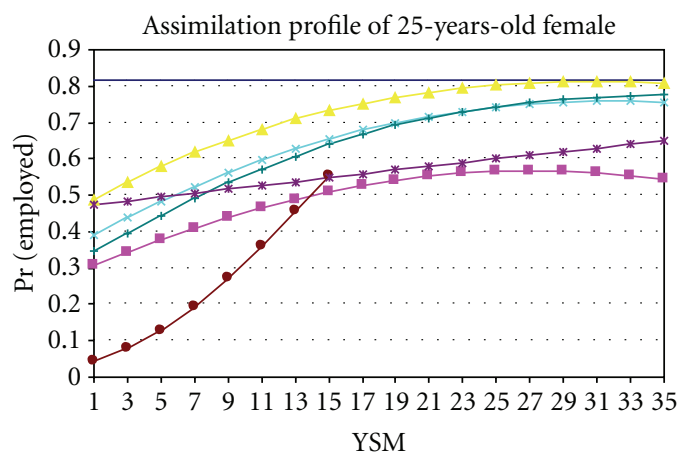

(b)

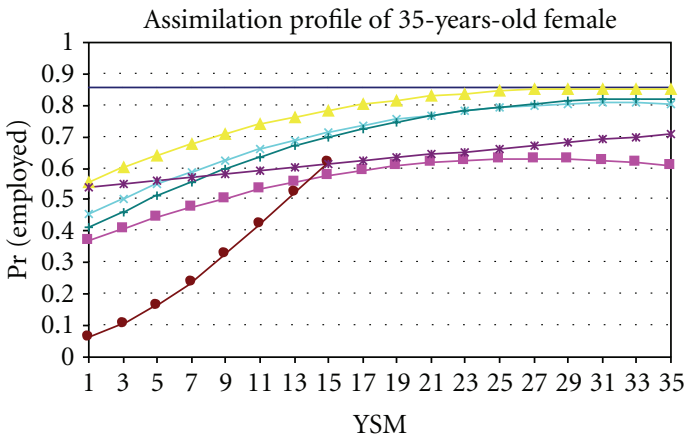

(d)

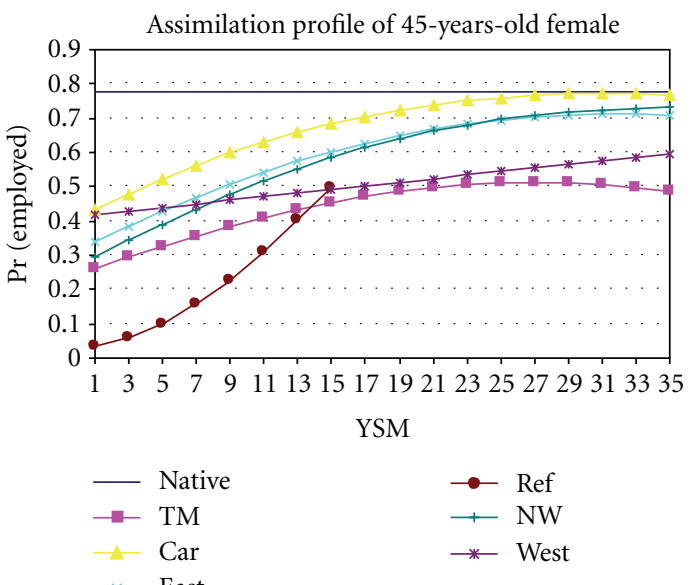

(f)

Figure 2: Probability of employment by years since migration, for different ages at arrival.

rather than maintain 11 categories as otherwise we would have too low frequencies in some classes.

Table 4 shows the distribution of natives and immigrants across the occupational classes. Nonwestern immigrants are highly concentrated in the category working class jobs, while the occupational distribution of western immigrants is closer to that of natives. Among immigrants, the categories TurkMoroc, refugee, and nonwestern migrants are overrepresented in working class jobs. Caribbean migrants have a better position than other nonwestern migrants. Native and western men have more likely service class jobs compared to their female counterparts, while the opposite holds for women from the other categories (TurkMoroc, Refugee, and Eastern-European).

The distribution of the employed labour force across these job categories is no doubt largely determined by individual background variables. To assess ethnic differences in the distribution, we study determinants of being in one of the three job types by regression models. We will not impose a strict ranking assumption on the job classes and model the probability of being in one of the occupational classes as a multinomial choice process; this avoids imposing 
TABLE 4: Distribution of natives and immigrants $25-64$ by job class; percentages (weighted).

\begin{tabular}{|c|c|c|c|c|c|c|}
\hline & \multicolumn{3}{|c|}{ Men } & \multicolumn{3}{|c|}{ Women } \\
\hline & Service & Interm & Working & Service & Interm & Working \\
\hline Native & 43.5 & 34.7 & 21.7 & 37.7 & 36.2 & 26.1 \\
\hline TurkMoroc & 15.4 & 26.8 & 57.9 & 17.7 & 26.8 & 55.4 \\
\hline Caribbean & 30.7 & 34.8 & 34.6 & 31.4 & 32.3 & 36.3 \\
\hline East European & 25.5 & 41.8 & 32.7 & 28.7 & 28.7 & 42.6 \\
\hline Refugee & 13.8 & 30.1 & 56.2 & 41.1 & 24.5 & 34.5 \\
\hline Other nonwest & 26.3 & 31.9 & 41.9 & 23.0 & 27.4 & 49.6 \\
\hline Western & 49.0 & 29.2 & 21.8 & 40.8 & 32.2 & 27.0 \\
\hline Total & 42.4 & 34.0 & 23.6 & 37.2 & 35.3 & 27.6 \\
\hline
\end{tabular}

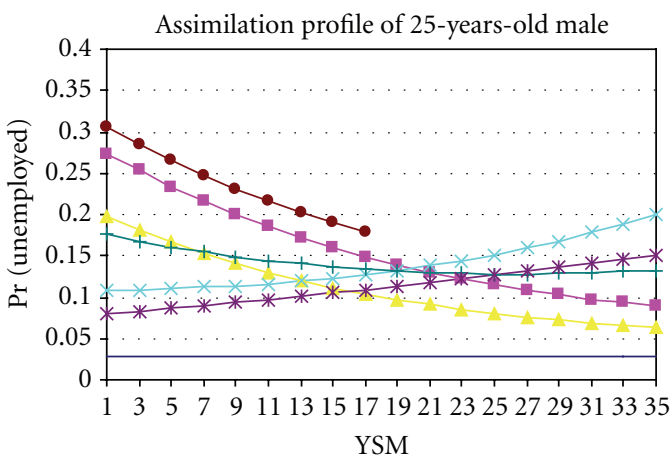

(a)

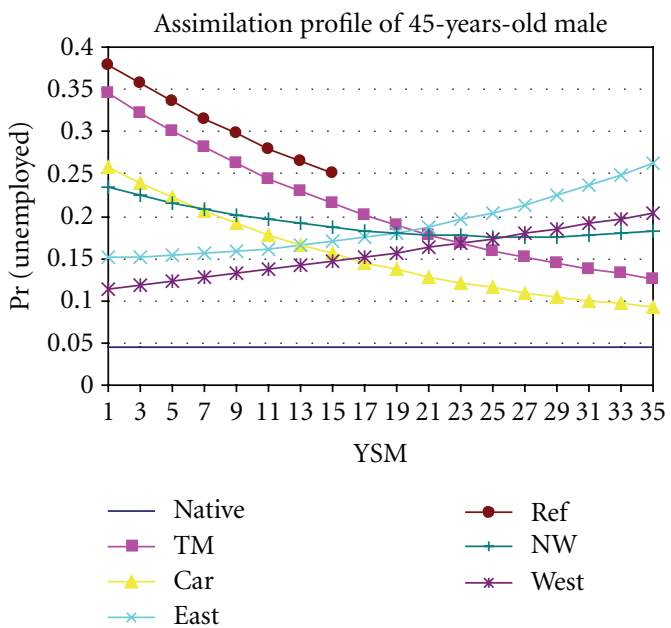

(c)

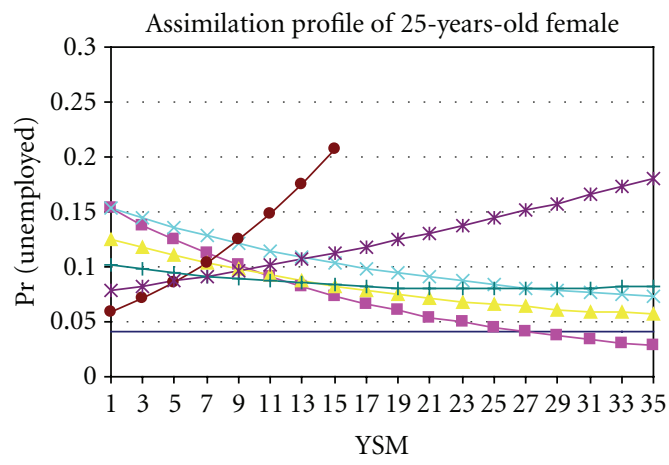

(b)

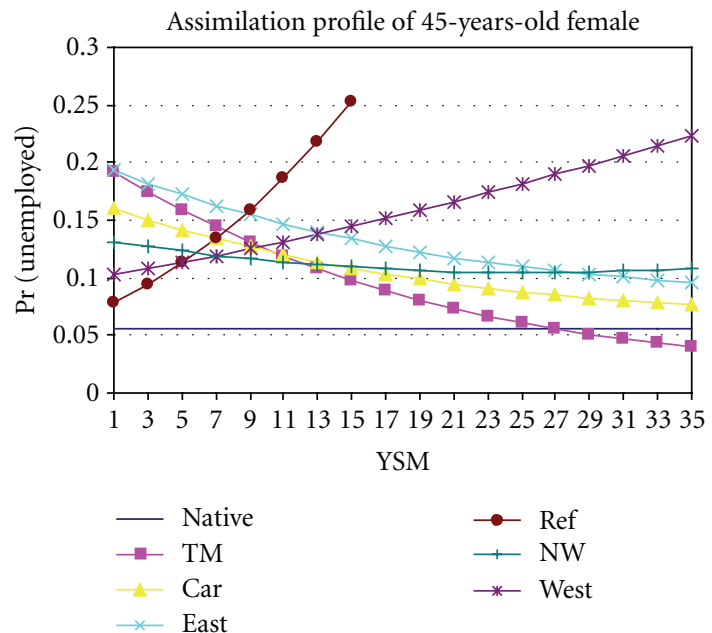

(d)

FIgURE 3: Probability of unemployment by years since migration, for different ages at arrival.

an underlying linear structure as in the ordered response model and maintains more modelling flexibility by treating each outcome separately relative to the base category. The coefficients for reference outcome 3 (working class jobs) are normalized to zero; thus, we estimate probabilities of having a service class or intermediate job, separate for men and women, relative to having a working class job.
6.1. Results. The estimates are presented in Tables 5(a) and 5(b). It is immediately apparent (and not surprising) that education level has a strong effect on the job class distribution: the pseudo- $\mathrm{R}^{2}$ shoots up if we include education. There is a strong positive effect of education on the probability of having service and intermediate class jobs relative to working class jobs, as expected (but not shown). 
Table 5: Determinants of service and intermediate jobs; multinomial odds ratios, (standard errors), and (marginal effects), men. Determinants of service and intermediate jobs; odds ratios, (standard errors), and (marginal effects), women.

(a)

\begin{tabular}{|c|c|c|c|c|c|c|c|c|}
\hline & \multicolumn{4}{|c|}{ Service } & \multicolumn{4}{|c|}{ Intermediate } \\
\hline & Mod I & Mod II & Mod III & Mod IV & Mod I & Mod II & Mod III & Mod IV \\
\hline \multirow{3}{*}{ Age } & $1.122^{* * *}$ & $1.201^{* * *}$ & $1.203^{* * *}$ & $1.130^{* * *}$ & 1.042 & $1.071^{* * *}$ & $1.072^{* * *}$ & 1.019 \\
\hline & $(0.010)$ & $(0.012)$ & $(0.012)$ & $(0.013)$ & $(0.010)$ & $(0.010)$ & $(0.010)$ & $(0.011)$ \\
\hline & {$[0.022]$} & {$[0.033]$} & {$[0.034]$} & {$[0.027]$} & {$[-0.008]$} & {$[-0.015]$} & {$[-0.015]$} & {$[-0.016]$} \\
\hline \multirow{3}{*}{ Age-sq } & $0.999^{* * *}$ & $0.998^{* * *}$ & $0.998^{* * *}$ & $0.999^{* * *}$ & $0.999^{* * *}$ & $0.999^{* * *}$ & $0.999^{* * *}$ & 1.000 \\
\hline & $(0.000)$ & $(0.000)$ & $(0.000)$ & $(0.000)$ & $(0.000)$ & $(0.000)$ & $(0.000)$ & $(0.000)$ \\
\hline & {$[-0.000]$} & {$[-0.000]$} & {$[-0.000]$} & {$[-0.000]$} & {$[0.000]$} & {$[0.000]$} & {$[0.000]$} & {$[0.000]$} \\
\hline \multirow{3}{*}{ YSM } & $1.030^{*}$ & $1.126^{* * *}$ & $1.122^{* * *}$ & $1.113^{* * *}$ & $1.060^{* * *}$ & $1.075^{* * *}$ & $1.073^{* * *}$ & $1.063^{* * *}$ \\
\hline & $(0.014)$ & $(0.018)$ & $(0.020)$ & $(0.021)$ & $(0.014)$ & $(0.015)$ & $(0.016)$ & $(0.016)$ \\
\hline & {$[-0.001]$} & {$[0.017]$} & {$[0.016]$} & {$[0.016]$} & [0.009] & {$[-0.003]$} & {$[-0.003]$} & {$[-0.004]$} \\
\hline \multirow{3}{*}{ YSM-sq } & 1.000 & $0.998^{* * *}$ & $0.998^{* * *}$ & $0.998^{* * *}$ & $0.999 * *$ & $0.999 * *$ & $0.999^{* *}$ & $0.999^{* *}$ \\
\hline & $(0.000)$ & $(0.000)$ & $(0.000)$ & $(0.000)$ & $(0.000)$ & $(0.000)$ & $(0.000)$ & $(0.000)$ \\
\hline & {$[0.000]$} & {$[-0.000]$} & {$[-0.000]$} & {$[-0.000]$} & {$[-0.000]$} & {$[0.000]$} & {$[0.000]$} & {$[0.000]$} \\
\hline \multirow{3}{*}{ TurkMoroc } & $0.080^{* * *}$ & $0.034^{* * *}$ & $0.037^{* * *}$ & $0.034^{* * *}$ & $0.143^{* * *}$ & $0.145^{* * *}$ & $0.149^{* * *}$ & $0.146^{* * *}$ \\
\hline & $(0.161)$ & $(0.210$ & $(0.240)$ & $(0.243)$ & $(0.147)$ & $(0.157)$ & $(0.178)$ & $(0.180)$ \\
\hline & {$[-0.317]$} & {$[-0.379]$} & {$[-0.374]$} & {$[-0.379]$} & {$[-0.186]$} & {$[-0.155]$} & {$[-0.152]$} & {$[-0.153]$} \\
\hline \multirow{3}{*}{ Caribbean } & $0.250^{* * *}$ & $0.093^{* * *}$ & $0.124^{* * *}$ & $0.111^{* * *}$ & $0.264^{* * *}$ & $0.217^{* * *}$ & $0.264^{* * *}$ & $0.251^{* * *}$ \\
\hline & $(0.160)$ & $(0.213)$ & $(0.244)$ & $(0.250)$ & $(0.156)$ & $(0.165)$ & $(0.198)$ & $(0.202)$ \\
\hline & {$[-0.174]$} & {$[-0.300]$} & {$[-0.273]$} & {$[-0.284]$} & {$[-0.131]$} & {$[-0.107]$} & {$[-0.078]$} & {$[-0.082]$} \\
\hline \multirow{3}{*}{ East-Europ } & $0.197^{* * *}$ & $0.035^{* * *}$ & $0.036^{* * *}$ & $0.038^{* * *}$ & $0.311^{* * *}$ & $0.185^{* * *}$ & $0.186^{* * *}$ & $0.199^{* * *}$ \\
\hline & $(0.180)$ & $(0.236)$ & $(0.297)$ & $(0.299)$ & $(0.166)$ & $(0.175)$ & $(0.225)$ & $(0.227)$ \\
\hline & {$[-0.225]$} & {$[0.376]$} & {$[-0.374]$} & {$[-0.373]$} & {$[-0.089]$} & {$[-0.115]$} & {$[-0.115]$} & {$[-0.099]$} \\
\hline \multirow{3}{*}{ RefugeeCount } & $0.123^{* * *}$ & $0.010^{* * *}$ & $0.003^{* * *}$ & $0.003^{* * *}$ & $0.195^{* * *}$ & $0.120^{* * *}$ & $0.084^{* * *}$ & $0.101^{* * *}$ \\
\hline & $(0.222)$ & $(0.284)$ & $(0.584)$ & $(0.591)$ & $(0.194)$ & $(0.208)$ & $(0.432)$ & $(0.439)$ \\
\hline & {$[-0.274]$} & {$[-0.414]$} & {$[-0.429]$} & {$[-0.429]$} & {$[-0.152]$} & {$[-0.185]$} & {$[-0.233]$} & {$[-0.206]$} \\
\hline \multirow{3}{*}{ Nonwestern } & $0.192^{* * *}$ & $0.045^{* * *}$ & $0.038^{* * *}$ & $0.040^{* * *}$ & $0.250^{* * *}$ & $0.195^{* * *}$ & $0.168^{* * *}$ & $0.188^{* * *}$ \\
\hline & $(0.158)$ & $(0.211)$ & $(0.256)$ & $(0.259)$ & $(0.150)$ & $(0.160)$ & $(0.197)$ & $(0.200)$ \\
\hline & {$[-0.218]$} & {$[-0.363]$} & {$[-0.371]$} & {$[-0.371]$} & {$[-0.127]$} & {$[-0.107]$} & {$[-0.133]$} & {$[-0.110]$} \\
\hline \multirow{3}{*}{ Western } & $0.416^{* * *}$ & $0.106^{* * *}$ & $0.102^{* * *}$ & $0.104^{* * *}$ & $0.302^{* * *}$ & $0.211^{* * *}$ & $0.208^{* * *}$ & $0.218^{* * *}$ \\
\hline & $(0.136)$ & $(0.183)$ & $(0.202)$ & $(0.206)$ & $(0.134)$ & $(0.142)$ & $(0.163)$ & $(0.164)$ \\
\hline & {$[-0.072]$} & {$[-0.285]$} & {$[-0.290]$} & {$[-0.289]$} & {$[-0.142]$} & {$[-0.105]$} & {$[-0.105]$} & {$[-0.096]$} \\
\hline \multirow{3}{*}{ Second Gen } & $3.264^{* * *}$ & $10.799^{* * *}$ & $10.969^{* * *}$ & $10.576^{* * *}$ & $3.271^{* * *}$ & $4.634^{* * *}$ & $4.619^{* * *}$ & $4.475^{* * *}$ \\
\hline & $(0.139)$ & $(0.185)$ & $(0.200)$ & $(0.203)$ & $(0.136)$ & $(0.145)$ & $(0.160)$ & $(0.161)$ \\
\hline & {$[0.083]$} & {$[0.277]$} & {$[0.281]$} & {$[0.278]$} & [0.069] & {$[-0.111]$} & {$[-0.114]$} & {$[-0.115]$} \\
\hline \multirow{3}{*}{ Caribb*YSM } & & & 0.987 & 0.982 & & & 0.989 & 0.982 \\
\hline & & & $(0.013)$ & $(0.013)$ & & & $(0.010)$ & $(0.010)$ \\
\hline & & & {$[-0.001]$} & {$[-0.001]$} & & & {$[-0.001]$} & {$[-0.001]$} \\
\hline \multirow{3}{*}{ EastEur*YSM } & & & 1.001 & 0.995 & & & 1.001 & 0.995 \\
\hline & & & $(0.022)$ & $(0.022)$ & & & $(0.016)$ & $(0.017)$ \\
\hline & & & {$[0.000]$} & {$[-0.000]$} & & & {$[0.000]$} & {$[-0.000]$} \\
\hline
\end{tabular}


(a) Continued.

\begin{tabular}{|c|c|c|c|c|c|c|c|c|}
\hline & \multicolumn{4}{|c|}{ Service } & \multicolumn{4}{|c|}{ Intermediate } \\
\hline & Mod I & Mod II & Mod III & Mod IV & Mod I & Mod II & Mod III & Mod IV \\
\hline \multirow{3}{*}{ Refug*YSM } & & & $1.143^{* *}$ & $1.136^{*}$ & & & 1.039 & 1.030 \\
\hline & & & $(0.051)$ & $(0.052)$ & & & $(0.041)$ & $(0.042)$ \\
\hline & & & {$[0.026]$} & {$[0.026]$} & & & {$[-0.013]$} & {$[-0.015]$} \\
\hline \multirow{3}{*}{ Non-west*YSM } & & & 1.019 & 1.010 & & & 1.013 & 1.002 \\
\hline & & & $(0.017)$ & $(0.017)$ & & & $(0.013)$ & $(0.013)$ \\
\hline & & & {$[0.002]$} & {$[0.002]$} & & & {$[0.000]$} & {$[-0.001]$} \\
\hline \multirow{3}{*}{ West*YSM } & & & 1.012 & 1.011 & & & 1.004 & 1.002 \\
\hline & & & $(0.012)$ & $(0.012)$ & & & $(0.009)$ & $(0.009)$ \\
\hline & & & {$[0.002]$} & {$[0.002]$} & & & {$[-0.001]$} & {$[-0.001]$} \\
\hline Log likelihood & -62734 & -48083 & -48075 & -47748 & & & & \\
\hline Pseudo R-sq & 0.01 & 0.24 & 0.24 & 0.25 & & & & \\
\hline$N$ & 59430 & 59430 & 59430 & 59430 & & & & \\
\hline
\end{tabular}

(b)

\begin{tabular}{|c|c|c|c|c|c|c|c|c|}
\hline & \multicolumn{4}{|c|}{ Service } & \multicolumn{4}{|c|}{ Intermediate } \\
\hline & Mod I & Mod II & Mod III & Mod IV & Mod I & Mod II & Mod III & Mod IV \\
\hline \multirow{3}{*}{ Age } & $0.935^{* * *}$ & 0.991 & 0.991 & $1.072^{* * *}$ & $0.974^{*}$ & 0.986 & 0.985 & 1.017 \\
\hline & $(0.011)$ & $(0.014)$ & $(0.014)$ & $(0.015)$ & $(0.011)$ & $(0.012)$ & $(0.012)$ & $(0.013)$ \\
\hline & {$[-0.012]$} & {$[-0.000]$} & {$[0.000]$} & {$[0.013]$} & {$[0.003]$} & {$[-0.002]$} & {$[-0.002]$} & {$[-0.006]$} \\
\hline \multirow{3}{*}{ Age-sq } & $1.000^{* * *}$ & 1.000 & 1.000 & $0.999 * *$ & 1.000 & 1.000 & 1.000 & 1.000 \\
\hline & $(0.000)$ & $(0.000)$ & $(0.000)$ & $(0.000)$ & $(0.000)$ & $(0.000)$ & $(0.000)$ & $(0.000)$ \\
\hline & {$[0.000]$} & {$[0.000]$} & {$[-0.000]$} & {$[-0.000]$} & {$[-0.000]$} & {$[0.000]$} & {$[0.000]$} & {$[0.000]$} \\
\hline \multirow{3}{*}{ YSM } & $1.041^{* *}$ & $1.078^{* * *}$ & $1.095^{* * *}$ & $1.091^{* * *}$ & $1.060^{* * *}$ & $1.065^{* * *}$ & $1.074^{* * *}$ & $1.072^{* * *}$ \\
\hline & $(0.015)$ & $(0.020)$ & $(0.023)$ & $(0.024)$ & $(0.015)$ & $(0.016)$ & $(0.019)$ & $(0.020)$ \\
\hline & [0.002] & {$[0.008]$} & {$[0.010]$} & [0.009] & {$[0.008]$} & {$[0.004]$} & {$[0.004]$} & {$[0.004]$} \\
\hline \multirow{3}{*}{ YSM-sq } & 0.999 & $0.999 *$ & $0.999 *$ & 0.999 & $0.999 *$ & $0.999 *$ & 0.999 & 0.999 \\
\hline & $(0.000)$ & $(0.000)$ & $(0.000)$ & $(0.000)$ & $(0.000)$ & $(0.000)$ & $(0.000)$ & $(0.000)$ \\
\hline & {$[-0.000]$} & {$[-0.000]$} & {$[-0.000]$} & {$[-0.000]$} & {$[-0.000]$} & {$[-0.000]$} & {$[-0.000]$} & {$[-0.000]$} \\
\hline \multirow{3}{*}{ TurkMoroc } & $0.088^{* * *}$ & $0.117^{* * *}$ & $0.095^{* * *}$ & $0.070 * * *$ & $0.101^{* * *}$ & $0.135^{* * *}$ & $0.117^{* * *}$ & $0.095^{* * *}$ \\
\hline & $(0.184)$ & $(0.248)$ & $(0.289)$ & $(0.296)$ & $(0.182)$ & $(0.201)$ & $(0.234)$ & $(0.242)$ \\
\hline & {$[-0.269]$} & {$[-0.221]$} & {$[-0.239]$} & {$[-0.256]$} & {$[-0.257]$} & {$[-0.249]$} & {$[-0.266]$} & {$[-0.293]$} \\
\hline \multirow{3}{*}{ Caribbean } & $0.287^{* * *}$ & $0.183^{* * *}$ & $0.190^{* * *}$ & $0.134^{* * *}$ & $0.229^{* * *}$ & $0.202^{* * *}$ & $0.201^{* * *}$ & $0.152^{* * *}$ \\
\hline & $(0.165)$ & $(0.224)$ & $(0.251)$ & $(0.254)$ & $(0.171)$ & $(0.187)$ & $(0.212)$ & $(0.218)$ \\
\hline & {$[-0.134]$} & {$[-0.176]$} & {$[-0.171]$} & {$[-0.200]$} & {$[-0.184]$} & {$[-0.196]$} & {$[-0.199]$} & {$[-0.236]$} \\
\hline \multirow{3}{*}{ East-Europ } & $0.267^{* * *}$ & $0.069^{* * *}$ & $0.073^{* * *}$ & $0.067 * * *$ & $0.225^{* * *}$ & $0.130^{* * *}$ & $0.142^{* * *}$ & $0.133^{* * *}$ \\
\hline & $(0.163)$ & $(0.221)$ & $(0.268)$ & $(0.271)$ & $(0.168)$ & $(0.180)$ & $(0.219)$ & $(0.224)$ \\
\hline & {$[-0.147]$} & {$[-0.269]$} & {$[-0.267]$} & {$[-0.265]$} & {$[-0.183]$} & {$[-0.244]$} & {$[-0.231]$} & {$[-0.243]$} \\
\hline \multirow{3}{*}{ RefugeeCount } & $0.450^{*}$ & $0.096^{* * *}$ & $0.131^{*}$ & $0.092 * *$ & $0.264^{* * *}$ & $0.151^{* * *}$ & $0.133^{* *}$ & $0.106^{* * *}$ \\
\hline & $(0.318)$ & $(0.430)$ & $(0.845)$ & $(0.833)$ & $(0.346)$ & $(0.367)$ & $(0.665)$ & $(0.666)$ \\
\hline & {$[-0.055]$} & {$[-0.243]$} & {$[-0.207]$} & {$[-0.234]$} & {$[-0.184]$} & {$[-0.228]$} & {$[-0.255]$} & {$[-0.283]$} \\
\hline \multirow{3}{*}{ Non-western } & $0.168^{* * *}$ & $0.056^{* * *}$ & $0.059^{* * *}$ & $0.050 * * *$ & $0.171^{* * *}$ & $0.127^{* * *}$ & $0.135^{* * *}$ & $0.120^{* * *}$ \\
\hline & $(0.163)$ & $(0.223)$ & $(0.264)$ & $(0.267)$ & $(0.164)$ & $(0.179)$ & $(0.213)$ & $(0.218)$ \\
\hline & {$[-0.208]$} & {$[-0.284]$} & {$[-0.282]$} & {$[-0.284]$} & {$[-0.207]$} & {$[-0.244]$} & {$[-0.236]$} & {$[-0.253]$} \\
\hline
\end{tabular}


(b) Continued.

\begin{tabular}{|c|c|c|c|c|c|c|c|c|}
\hline & \multicolumn{4}{|c|}{ Service } & \multicolumn{4}{|c|}{ Intermediate } \\
\hline & Mod I & Mod II & Mod III & Mod IV & Mod I & Mod II & Mod III & Mod IV \\
\hline \multirow{3}{*}{ Western } & $0.400^{* * *}$ & $0.164^{* * *}$ & $0.157^{* * *}$ & $0.142^{* * *}$ & $0.242^{* * *}$ & $0.164^{* * *}$ & $0.182^{* * *}$ & $0.163^{* * *}$ \\
\hline & $(0.144)$ & $(0.197)$ & $(0.212)$ & $(0.215)$ & $(0.152)$ & $(0.164)$ & $(0.179)$ & $(0.184)$ \\
\hline & {$[-0.068]$} & {$[-0.180]$} & {$[-0.191]$} & {$[-0.194]$} & {$[-0.194]$} & {$[-0.223]$} & {$[-0.200]$} & {$[-0.220]$} \\
\hline \multirow{3}{*}{ Second Gen } & $3.146^{* * *}$ & $6.523^{* * *}$ & $6.785^{* * *}$ & $6.607^{* * *}$ & $4.438^{* * *}$ & $5.996^{* * *}$ & $5.570^{* * *}$ & $5.764^{* * *}$ \\
\hline & $(0.146)$ & $(0.200)$ & $(0.210)$ & $(0.213)$ & $(0.154)$ & $(0.167)$ & $(0.176)$ & $(0.181)$ \\
\hline & {$[0.020]$} & {$[0.107]$} & {$[0.133]$} & {$[0.113]$} & {$[0.173]$} & [0.089] & {$[0.062]$} & {$[0.074]$} \\
\hline \multirow{3}{*}{ Caribb*YSM } & & & 0.982 & 0.976 & & & 0.987 & 0.982 \\
\hline & & & $(0.016)$ & $(0.016)$ & & & $(0.013)$ & $(0.013)$ \\
\hline & & & {$[-0.002]$} & {$[-0.003]$} & & & {$[-0.001]$} & {$[-0.001]$} \\
\hline \multirow{3}{*}{ EastEur*YSM } & & & 0.979 & 0.972 & & & 0.979 & 0.973 \\
\hline & & & $(0.022)$ & $(0.022)$ & & & $(0.017)$ & $(0.018)$ \\
\hline & & & {$[-0.002]$} & {$[-0.002]$} & & & {$[-0.002]$} & {$[-0.002]$} \\
\hline \multirow{3}{*}{ Refug*YSM } & & & 0.960 & 0.972 & & & 0.998 & 1.001 \\
\hline & & & $(0.065)$ & $(0.064)$ & & & $(0.050)$ & $(0.049)$ \\
\hline & & & {$[-0.009]$} & {$[-0.006]$} & & & {$[0.006]$} & {$[0.004]$} \\
\hline \multirow{3}{*}{ Non-west*YSM } & & & 0.981 & 0.973 & & & 0.983 & 0.972 \\
\hline & & & $(0.019)$ & $(0.020)$ & & & $(0.015)$ & $(0.016)$ \\
\hline & & & {$[-0.002]$} & {$[-0.002]$} & & & {$[-0.001]$} & {$[-0.003]$} \\
\hline \multirow{3}{*}{ West*YSM } & & & 0.988 & 0.984 & & & $0.976^{*}$ & $0.973^{*}$ \\
\hline & & & $(0.014)$ & $(0.015)$ & & & $(0.012)$ & $(0.012)$ \\
\hline & & & {$[0.001]$} & {$[0.001]$} & & & {$[-0.004]$} & {$[-0.004]$} \\
\hline Log likelihood & -51840 & -37874 & -37869 & -36726 & & & & \\
\hline Pseudo R-sq & 0.01 & 0.28 & 0.28 & 0.30 & & & & \\
\hline$N$ & 48161 & 48161 & 48161 & 48161 & & & & \\
\hline
\end{tabular}

$P<.05 ; * * P<.01 ; * * * P<.001$.

Models II and III also include dummies for 7 categories of educational achievement. Model IV also includes 3 dummy variables for the presence of children below 11 years and controls for marital status, the degree of urbanisation, and naturalisation of immigrants and working hours.

Remarkably, immigrants are still significantly less likely in service and intermediate class jobs after controlling for age, education, and family status. The estimated marginal effects for categorical variables indicate differences with respect to the reference category in a certain outcome. The marginal effects for the origin countries show the ethnic difference in the representation in the separate outcomes, since native is the reference category. So, positive marginal effects for a particular origin group reflect an overrepresentation of this group in that outcome while negative marginal effects reflect an underrepresentation. For instance, considering model IV in Table 5(a), the marginal effects for TurkMor -0.379 and -0.153 indicate that the shares of Turks and Moroccans in service and intermediate jobs are 37.9 and 15.3 percent lower than for natives in these jobs.

The initial probability of having service class jobs upon arrival is about 37 percentage points lower for immigrant men from Turkey/Morocco and East Europe than for native men, as indicated by marginal effects for the origin fixed effects in model IV. Male immigrants from the Caribbean and western source countries experience an initial disadvantage of about 28 percentage points relative to natives. This gap is the highest for refugee men (43 percentage points). The initial gap for service class jobs is relatively smaller for immigrant women relative to native women, and the variation between the origin groups is relatively small, ranging from 19 to 26 percentage points.

The initial ethnic gap for intermediate jobs is relatively lower for immigrant men, compared to service class jobs: about 15 percentage points for Turks/Moroccans and 89 points for Caribbean, Eastern European, and Western immigrants. However, it is relatively larger for immigrant women, varying from 22 to 29 percentage points. These ethnic gaps decline at a diminishing rate with additional year of residence (YSM). The decline is sharper for refugees as indicated by an interaction of the origin-fixed effect with YSM. The probability of having service class and intermediate jobs will reach its maximum after circa 30 years of residence for immigrant men and 50 to 60 years of residence for immigrant women ${ }^{11}$. Note that in particular 


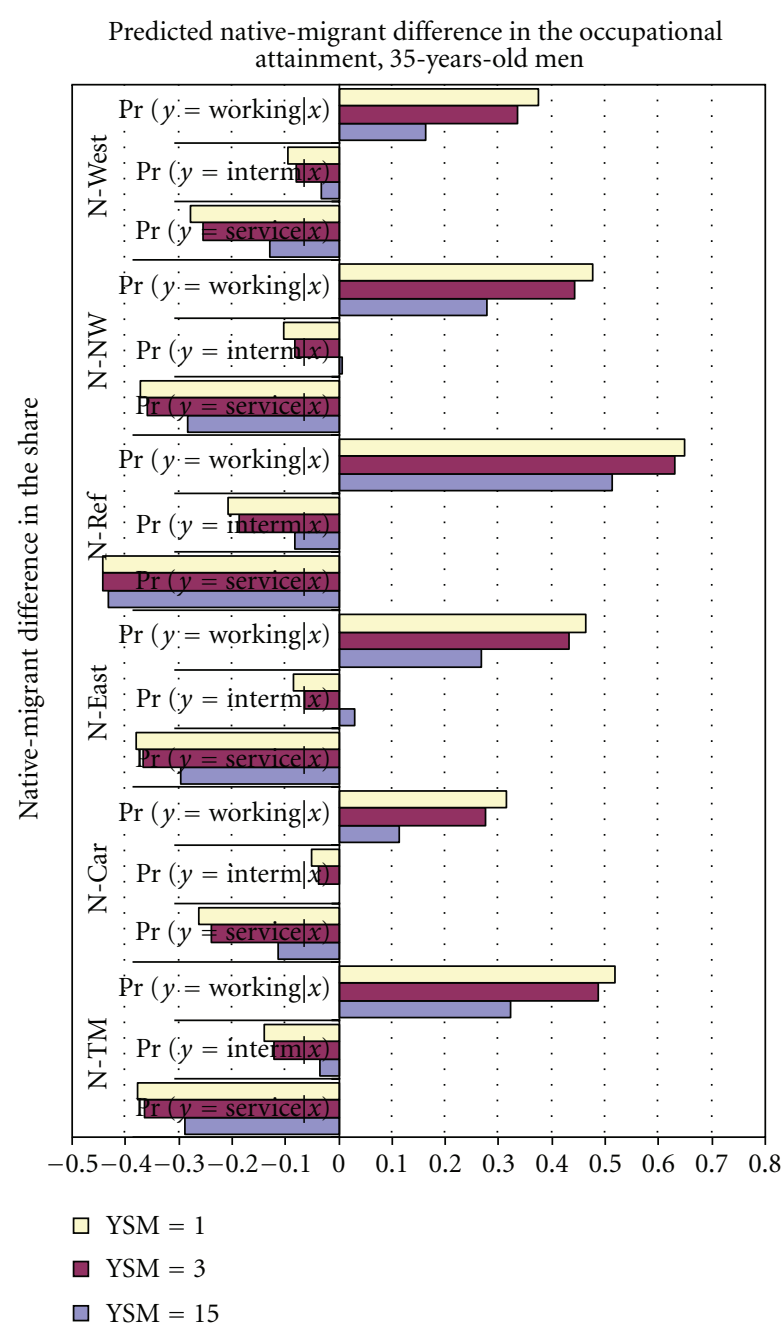

(a)

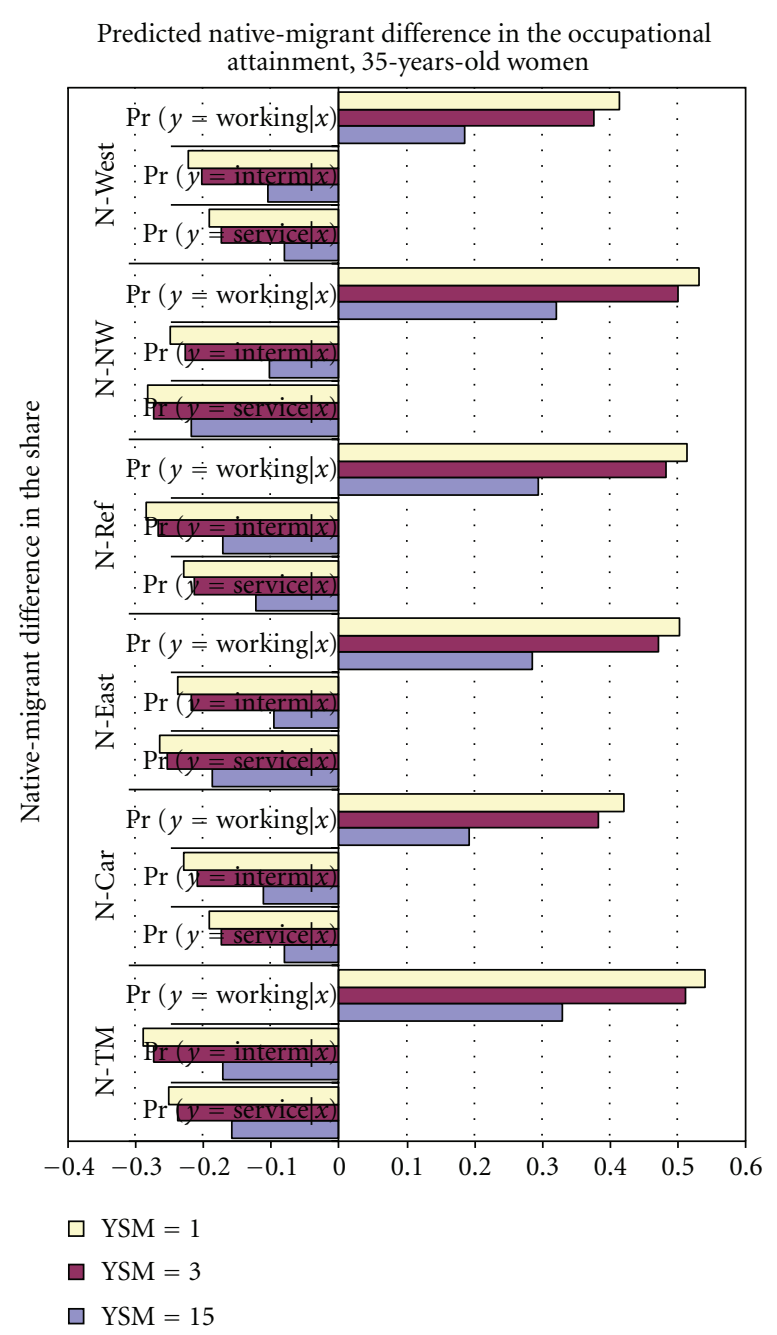

(b)

FIGURE 4: Distribution of occupational quality: probability for natives minus probability of immigrant groups (source: Tables 6 and 7, Model IV).

for service jobs, controlling for education (Model II versus Model I) increases, rather than decreases, the effect of ethnicity.

6.2. Simulations. With the results in Table 5, we have simulated the distribution of occupational quality over three levels (Figure 4): we put all variables at their sample means, hold age constant at 35, and show the effect of YSM. Not surprisingly, immigrants are concentrated at lower occupational levels. They are overrepresented in working class jobs and underrepresented in intermediate and service jobs. But remarkably, this holds for all immigrant groups, including those from western countries. In all cases, the excessive concentration in working class jobs, relative to natives, decreases over time, and is generally reduced to about half its original value in 15-year time (except for refugees). The excess concentration in working class jobs is somewhat stronger for women than for men, though not excessively so. None of the groups reaches parity in 15-year time, and in that sense we can say that for none of these groups is there successful integration within a reasonable time span.

\section{Distance, Dip, and Catchup}

In Section 3, we set up a ranking of source countries by presumed sociocultural distance and hence, ease of skill transferability. Lacking good measures of distance and transferability, the ranking is somewhat speculative, but we believe that our ranking would be shared by many analysts. In fact, employment and unemployment probabilities already appeared to support this a priori ranking. Duleep and Regets [10] extract the prediction from human capital theory that lower skill transferability would lead to a larger initial performance gap but faster catching up with comparable natives. We will now focus on these predictions. 
Employment

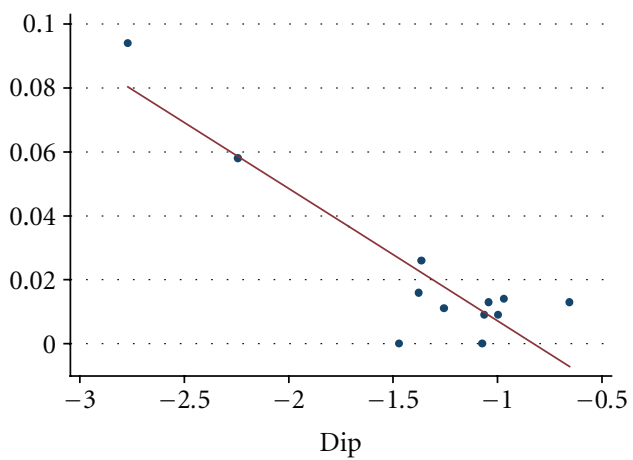

(a)

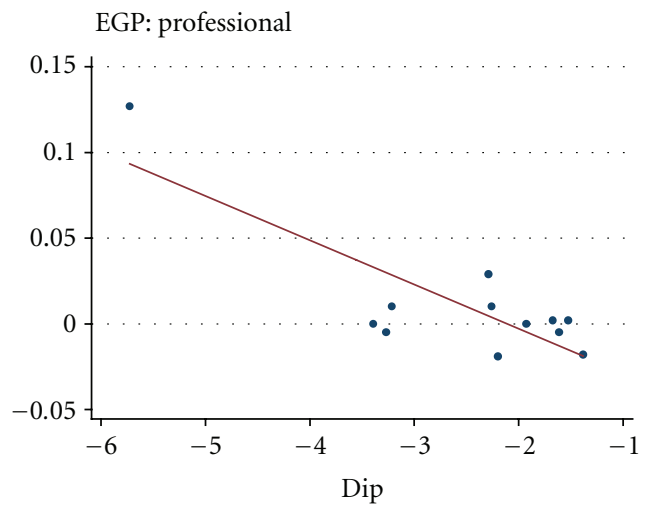

(c)
Unemployment

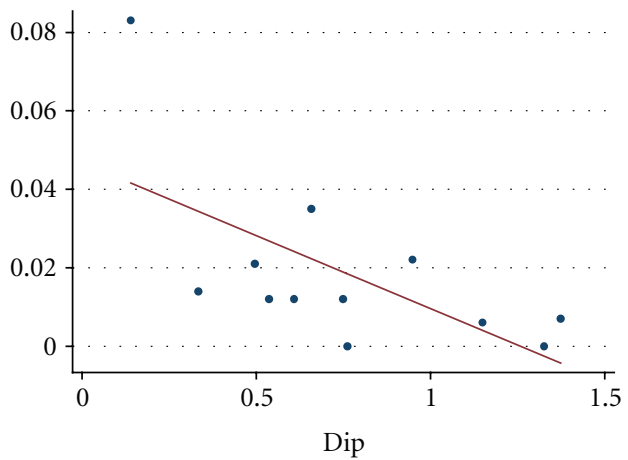

(b)

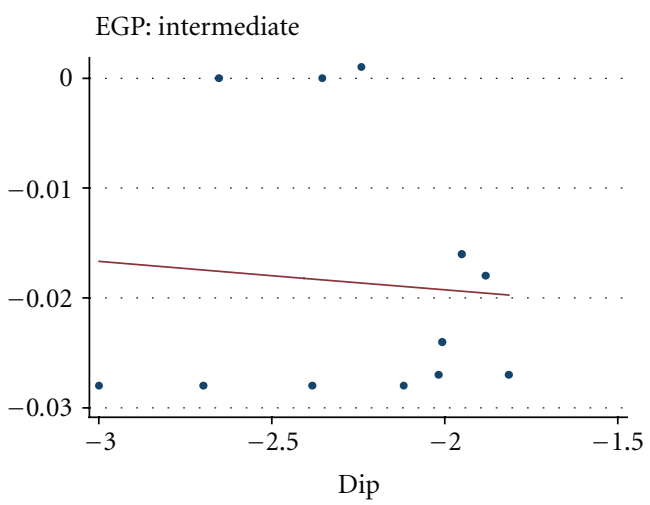

(d)

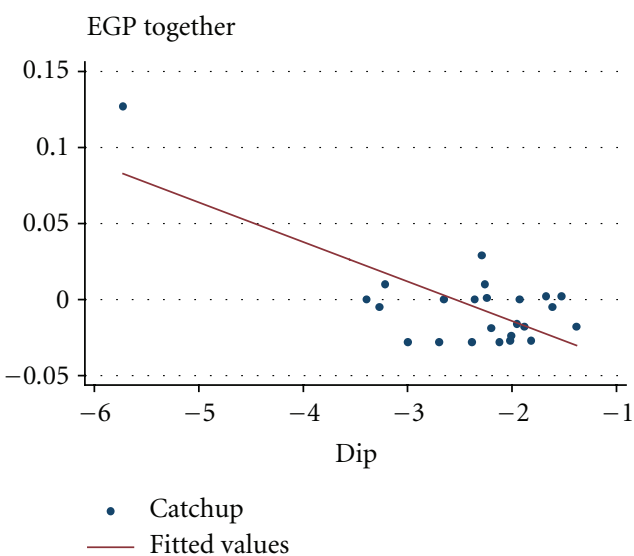

(e)

FIGURE 5: Scatter diagrams of dip and catchup (country-specific intercepts and country-specific coefficients on YSM; Model IV).

In Figure 5, we have plotted dip and catchup by source country. Dip is measured by the source country immigrant dummy (i.e., the gap between immigrant and native at entry). Catchup is measured by the sum of slope of YSM and the interaction term on YSM and country dummy: the effect of years-since-migration for that country (we ignored the coefficient on the square of YSM, as it is mostly small and barely varies among countries). In all cases we take the coefficients from Model IV, that is, the most extensive specification. The coefficients are plotted in the sequence we hypothesized on the basis of presumed skill transferability to The Netherlands; we would expect a monotonic ordering of the coefficients.

Predictions are borne out reasonably well for the probabilities of employment and unemployment. In fact, the outcome for male employment is perfect (just as it was for the unstandardised case). We can count the minimum number of coefficients that should be ignored to retain a monotonic outcome in the desired direction. For example, if we ignore the Caribbean and the nonwestern coefficients for 


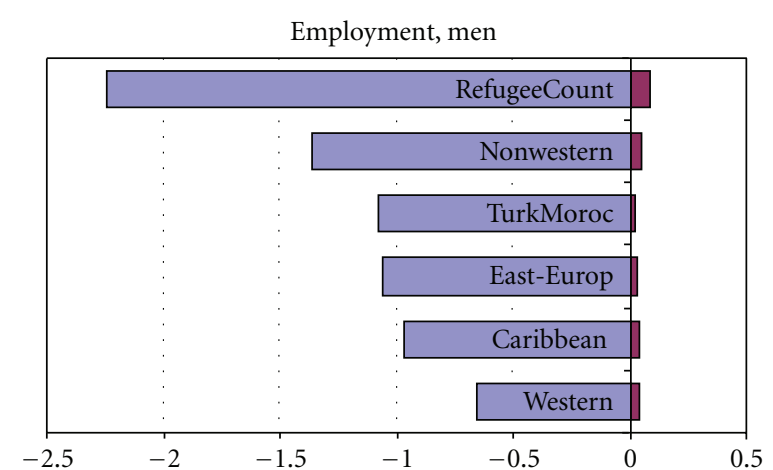

(a)

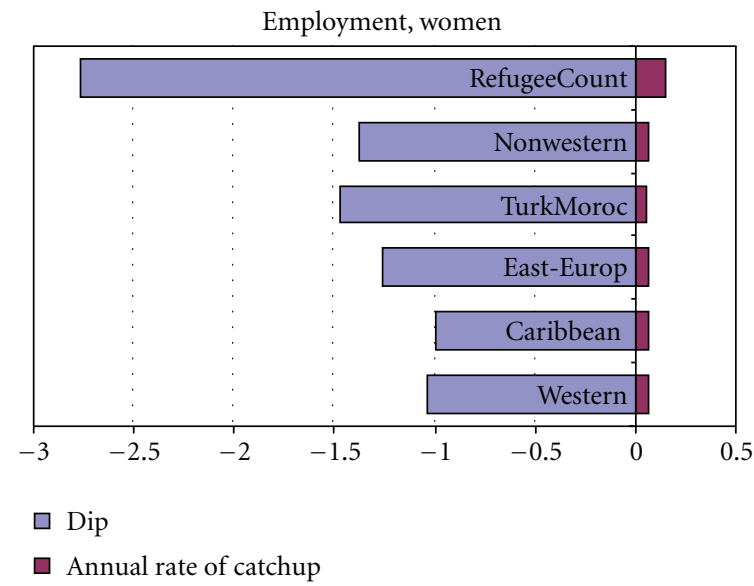

(c)

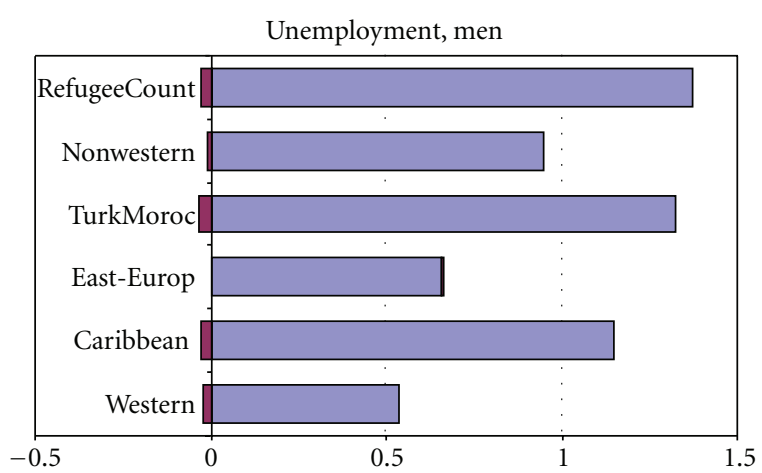

(b)

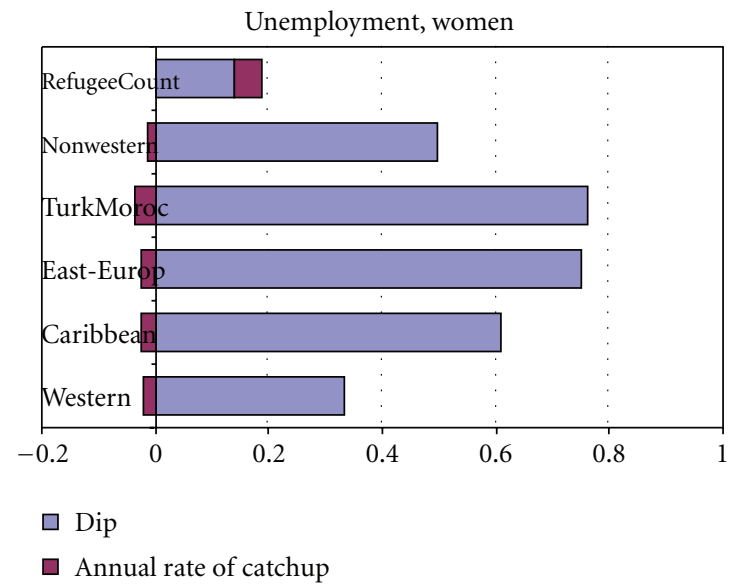

(d)

Figure 6: Dip and catchup by sociocultural distance. "Dip" is the country-specific intercept and "Catchup" the country-specific coefficient on years-since-migration plus the interaction coefficient in the regressions in Tables 2 and 3 (Model IV).

female employment, the remaining four coefficients exhibit the predicted monotonic decrease. Except for male catchup on unemployment, none of the series requires to remove more than 2 coefficients (and the score is better if we remember that we could not really rank Turks/Moroccans versus other non-western). The score for male catch-up on unemployment is completely out of step though. The scores on occupational level are reasonably close to a monotonic sequence, in particular for the initial dips. Differences in catch-up rates are very small; with only three grades of occupational level, there is neither much difference with the lifetime mobility of natives (as measured by age) nor among immigrants from different source countries.

To test the prediction of a negative relationship between dip and catch-up, we have plotted scatters for dip and catch-up: as in Figure 5, from each regression we take the source country intercept and the sum of the coefficients on YSM and on source country interaction with YSM (Figure 6). As we combine the data points for men and women, each graph has 12 observations. The anticipated negative relationship (faster catch-up after a deeper dip) is supported reasonably well, more so for employment and unemployment than for the occupational level (where we use the coefficients, not the odds ratio's. Regression analyses confirm this impression. Naturally, these exercises are more illustrative than solid empirical evidence, if only for the limited number of observations.

$$
\text { Employment: }
$$

$$
\begin{gathered}
\text { Catch-Up }=-0.0342(-3.61)-0.0414(-6.42) \text { Dip, } \\
N=12, \quad R^{2}=0.80 .
\end{gathered}
$$

Unemployment:

$$
\begin{gathered}
\text { Catch-Up }=0.0468(-3.85)-0.0372(-2.57) \text { Dip, } \\
N=12, \quad R^{2}=0.40 .
\end{gathered}
$$

$$
\begin{aligned}
& \text { Separate EGP: } \\
& \text { professional } \\
& \text { Catch-Up }=-0.0545(-3.40)-0.0258(-4.50) \text { Dip, } \\
& \qquad N=12, \quad R^{2}=0.67
\end{aligned}
$$


Intermediate

$$
\begin{gathered}
\text { Catch-Up }=-0.0245(-1.04)-0.0026(-0.25) \text { Dip, } \\
N=12, R^{2}=0.006 .
\end{gathered}
$$

EGP together:

$$
\begin{gathered}
\text { Catch-Up }=0.0661(5.00)-0.0259(-5.03) \text { Dip, } \\
N=24, R^{2}=0.67
\end{gathered}
$$

\section{Conclusions}

We have studied the position of immigrants in The Netherlands using a large cross-section dataset for 2004 and 2005. We measure the gap at entry between immigrants and natives conditional on some socioeconomic variables, and we measure assimilation profiles in function of years since migration. While admittedly this assignment of differences between cohorts over time to longitudinal effects may be invalidated by unobserved quality differences and selective emigration, we have given reasons not to worry too much about such bias. We find some usual and hence anticipated results, such as poor performance of immigrants from nonwestern countries (including poor results for the second generation) and much better performance of immigrants from western source countries. But we also report several novel and not fully anticipated results.

The analysis has shown that nonwestern immigrants are substantially less likely employed. The employment level of western immigrants is quite close to that of natives. Among nonwestern immigrants, the labour market position of immigrants from former colonies in the Caribbean (Surinam and Dutch Antilles) is the best, although these immigrants are still significantly disadvantaged compared to natives. The significant higher performance of women from this group is remarkable. The participation rate of nonwestern immigrants is still very low, and they are employed in low-quality jobs, conditional on the relevant characteristics observed. The probability of participation and employment as well as quality of jobs is low upon arrival, but increases significantly with the duration of stay.

As the working population is considered, the same disadvantaged immigrant groups are less likely in professional and managerial jobs and highly concentrated in working class jobs. Immigrants start with a low-qualified job upon arrival and the quality of job significantly goes up with the time elapsed in the Netherlands, although the final position remains lower than for natives.

Comparing with native gender counterparts, immigrant men are in general relatively more disadvantaged than immigrant women. Only among Turkish and Moroccan immigrants, the active participation rate of women is relatively low. Especially immigrant men from Iran, Iraq, and Afghanistan, who likely entered as refugees, are less likely active in the labour market. Their low participation rate is possibly related to their particular position. During their asylum application, they are not allowed to work. High unemployment and low job quality can indicate a difficult starting position due to depreciation of their human capital endowment during the forced idleness (Hartog and Zorlu, forthcoming).

Comparing immigrant groups, we found that in terms of employment probability, Turks/Moroccans perform worst, Caribbeans and western men perform best. The bigger the initial employment gap for an origin group, the steeper the effect of years since migration: employment probabilities converge over time. Also, convergence appears stronger for men than for women. Unemployment probabilities do not develop uniformly with time since migration: they generally decrease and approach levels for natives, but they increase for western immigrants, for East European men and for refugee women.

We have also considered assimilation in terms of type of jobs. The gap in occupational quality between natives and immigrants appears larger for women than for men. Just like all other immigrant groups, immigrants from nonwestern countries are more likely to work in working class jobs than natives (even when controlling for education!).

Tentative analysis, necessarily based on few data points, supports our notion of sociocultural distance as an important factor in integration in the Netherlands. Also, we find general support for the Duleep-Regets hypothesis of a negative relationship between dip and catchup, that is, faster catching up after starting out at a larger initial gap with natives. Our tentative and perhaps rather illustrative results suggest that both the hypothesis of a strong effect of sociocultural distance and the Duleep-Regets hypothesis are worth maintaining for further empirical investigation.

The evidence of low initial employment level and job quality of immigrants, related to the cultural and linguistic distance of immigrants to Dutch society, suggests that effective policies should aim to narrow the larger initial gaps a soon as possible, preferably without reducing the speed of catching up. Fast and intensive language training can help to close the initial gap and will pay off directly in the Dutch labour market. In addition, communication training can facilitate immigrants to operate in a new environment, learn the functioning of relevant institutions, and find employment, while specific professional training programmes can prevent skill mismatch so that immigrants will perform their original occupation in the Netherlands. Skill transferability can probably also be improved by providing information to prospective employers about the quality of homeland schooling and training, to reduce uncertainty surrounding hiring an immigrant.

\section{Appendix}

See Tables 6 and 7 . 
TABLE 6: Predicted probabilities EGP job class, men.

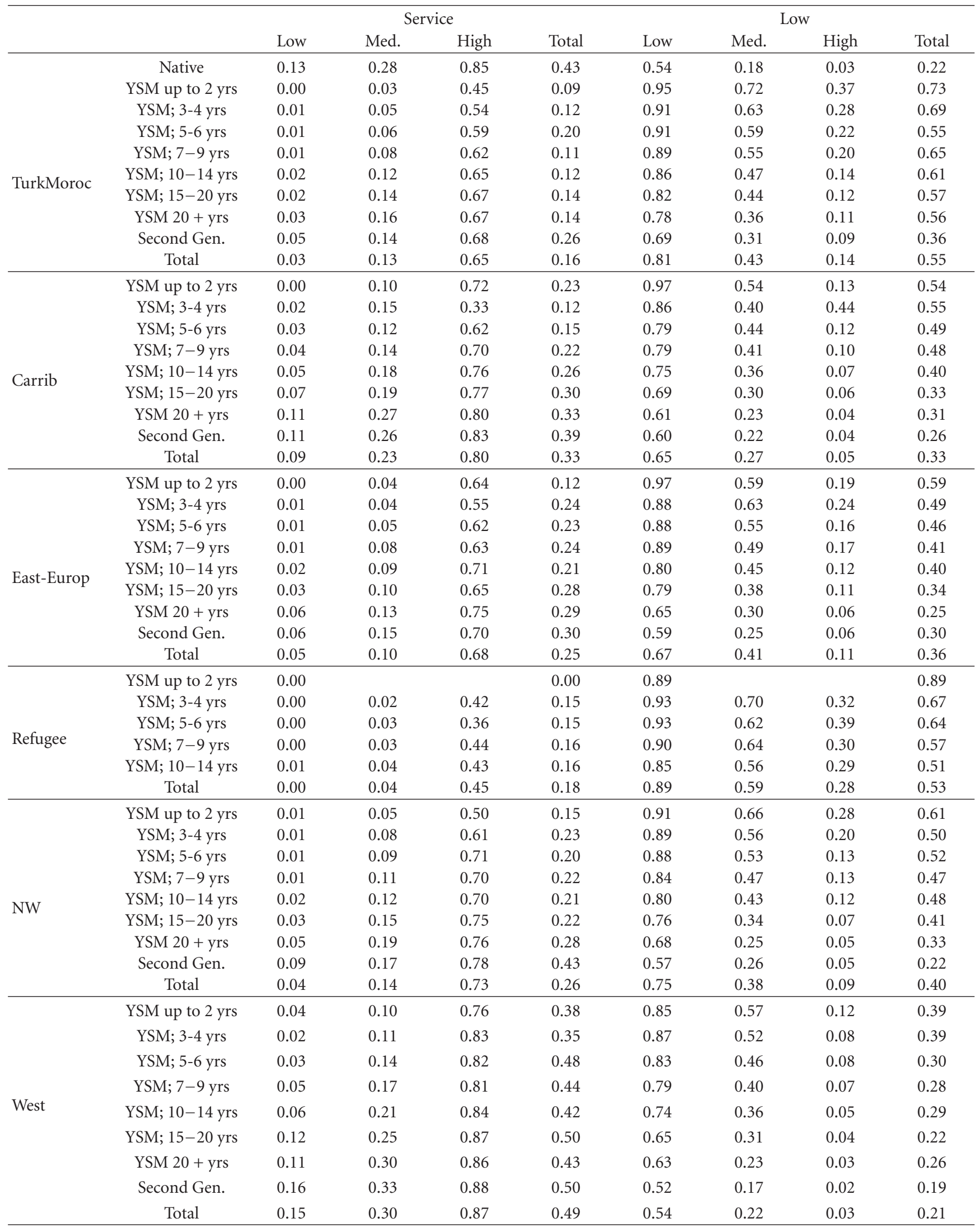


Table 7: Predicted probabilities EGP job class, women.

\begin{tabular}{|c|c|c|c|c|c|c|c|c|c|}
\hline & \multicolumn{4}{|c|}{ Service } & \multicolumn{4}{|c|}{ Low } \\
\hline & & Low & Med & High & Total & Low & Med & High & Total \\
\hline \multirow{10}{*}{ TurkMoroc } & Native & 0.08 & 0.20 & 0.80 & 0.37 & 0.70 & 0.20 & 0.03 & 0.26 \\
\hline & YSM up to 2 yrs & 0.00 & 0.03 & & 0.02 & 0.98 & 0.77 & & 0.88 \\
\hline & YSM; 3-4 yrs & & 0.07 & 0.72 & 0.35 & & 0.71 & 0.17 & 0.48 \\
\hline & YSM; 5-6 yrs & 0.01 & 0.08 & & 0.04 & 0.96 & 0.61 & & 0.83 \\
\hline & YSM; 7-9 yrs & 0.02 & 0.12 & 0.84 & 0.13 & 0.93 & 0.54 & 0.06 & 0.70 \\
\hline & YSM; $10-14$ yrs & 0.02 & 0.12 & 0.78 & 0.14 & 0.92 & 0.52 & 0.09 & 0.66 \\
\hline & YSM; $15-20$ yrs & 0.03 & 0.12 & 0.75 & 0.13 & 0.90 & 0.49 & 0.09 & 0.69 \\
\hline & YSM $20+$ yrs & 0.04 & 0.15 & 0.80 & 0.15 & 0.87 & 0.41 & 0.06 & 0.61 \\
\hline & Second Gen. & 0.06 & 0.18 & 0.79 & 0.28 & 0.74 & 0.21 & 0.04 & 0.31 \\
\hline & Total & 0.04 & 0.15 & 0.78 & 0.19 & 0.87 & 0.37 & 0.06 & 0.54 \\
\hline \multirow{9}{*}{ Carrib } & YSM up to 2 yrs & 0.02 & 0.20 & 0.52 & 0.19 & 0.94 & 0.40 & 0.32 & 0.65 \\
\hline & YSM; 3-4 yrs & 0.04 & 0.10 & 0.80 & 0.15 & 0.88 & 0.56 & 0.06 & 0.64 \\
\hline & YSM; 5-6 yrs & 0.03 & 0.14 & 0.70 & 0.32 & 0.89 & 0.42 & 0.14 & 0.42 \\
\hline & YSM; 7-9 yrs & 0.03 & 0.17 & 0.71 & 0.25 & 0.89 & 0.40 & 0.12 & 0.47 \\
\hline & YSM; $10-14$ yrs & 0.04 & 0.17 & 0.76 & 0.28 & 0.86 & 0.37 & 0.08 & 0.42 \\
\hline & YSM; 15-20 yrs & 0.05 & 0.16 & 0.77 & 0.27 & 0.82 & 0.36 & 0.07 & 0.39 \\
\hline & YSM $20+$ yrs & 0.06 & 0.20 & 0.78 & 0.29 & 0.81 & 0.30 & 0.06 & 0.41 \\
\hline & Second Gen. & 0.11 & 0.21 & 0.80 & 0.41 & 0.64 & 0.17 & 0.03 & 0.20 \\
\hline & Total & 0.06 & 0.19 & 0.78 & 0.31 & 0.79 & 0.29 & 0.06 & 0.36 \\
\hline \multirow{9}{*}{ East-Eur } & YSM up to 2 yrs & 0.01 & 0.06 & 0.51 & 0.21 & 0.95 & 0.63 & 0.35 & 0.56 \\
\hline & YSM; 3-4 yrs & 0.01 & 0.07 & 0.63 & 0.32 & 0.95 & 0.61 & 0.22 & 0.45 \\
\hline & YSM; 5-6 yrs & 0.01 & 0.09 & 0.68 & 0.34 & 0.94 & 0.54 & 0.17 & 0.42 \\
\hline & YSM; 7-9 yrs & 0.01 & 0.08 & 0.67 & 0.27 & 0.94 & 0.56 & 0.16 & 0.45 \\
\hline & YSM; $10-14$ yrs & 0.01 & 0.09 & 0.67 & 0.28 & 0.93 & 0.53 & 0.16 & 0.44 \\
\hline & YSM; $15-20$ yrs & 0.01 & 0.11 & 0.73 & 0.19 & 0.93 & 0.45 & 0.12 & 0.43 \\
\hline & YSM $20+$ yrs & 0.03 & 0.11 & 0.73 & 0.32 & 0.84 & 0.45 & 0.09 & 0.40 \\
\hline & Second Gen. & 0.04 & 0.12 & 0.72 & 0.30 & 0.78 & 0.26 & 0.05 & 0.31 \\
\hline & Total & 0.03 & 0.09 & 0.68 & 0.29 & 0.86 & 0.49 & 0.15 & 0.42 \\
\hline \multirow{6}{*}{ Refugee } & YSM up to 2 yrs & & & & & & & & \\
\hline & YSM; 3-4 yrs & & 0.13 & & 0.13 & & 0.45 & & 0.45 \\
\hline & YSM; 5-6 yrs & & 0.09 & 0.74 & 0.31 & & 0.55 & 0.13 & 0.41 \\
\hline & YSM; 7-9 yrs & 0.01 & 0.12 & 0.63 & 0.30 & 0.97 & 0.48 & 0.21 & 0.42 \\
\hline & YSM; $10-14$ yrs & 0.02 & 0.13 & 0.78 & 0.41 & 0.90 & 0.45 & 0.09 & 0.35 \\
\hline & Total & 0.03 & 0.13 & 0.72 & 0.39 & 0.88 & 0.45 & 0.13 & 0.34 \\
\hline \multirow{9}{*}{ NW } & YSM up to 2 yrs & 0.01 & 0.04 & 0.55 & 0.18 & 0.97 & 0.72 & 0.29 & 0.66 \\
\hline & YSM; 3-4 yrs & 0.01 & 0.05 & 0.55 & 0.23 & 0.97 & 0.65 & 0.30 & 0.58 \\
\hline & YSM; 5-6 yrs & 0.01 & 0.06 & 0.58 & 0.20 & 0.94 & 0.62 & 0.26 & 0.59 \\
\hline & YSM; 7-9 yrs & 0.01 & 0.07 & 0.59 & 0.17 & 0.94 & 0.57 & 0.23 & 0.57 \\
\hline & YSM; $10-14$ yrs & 0.02 & 0.09 & 0.65 & 0.19 & 0.91 & 0.52 & 0.17 & 0.55 \\
\hline & YSM; $15-20$ yrs & 0.02 & 0.09 & 0.64 & 0.17 & 0.90 & 0.47 & 0.14 & 0.53 \\
\hline & YSM $20+$ yrs & 0.02 & 0.10 & 0.66 & 0.24 & 0.89 & 0.43 & 0.13 & 0.46 \\
\hline & Second Gen. & 0.06 & 0.10 & 0.69 & 0.37 & 0.69 & 0.29 & 0.07 & 0.22 \\
\hline & Total & 0.02 & 0.08 & 0.64 & 0.23 & 0.90 & 0.49 & 0.16 & 0.49 \\
\hline \multirow{9}{*}{ West } & YSM up to 2 yrs & & 0.12 & 0.77 & 0.47 & & 0.58 & 0.14 & 0.34 \\
\hline & YSM; 3-4 yrs & 0.02 & 0.15 & 0.80 & 0.36 & 0.94 & 0.50 & 0.10 & 0.42 \\
\hline & YSM; 5-6 yrs & 0.05 & 0.18 & 0.80 & 0.44 & 0.85 & 0.45 & 0.09 & 0.31 \\
\hline & YSM; 7-9 yrs & 0.03 & 0.15 & 0.82 & 0.42 & 0.88 & 0.46 & 0.08 & 0.33 \\
\hline & YSM; $10-14$ yrs & 0.04 & 0.17 & 0.82 & 0.39 & 0.88 & 0.42 & 0.07 & 0.32 \\
\hline & YSM; $15-20$ yrs & 0.03 & 0.19 & 0.82 & 0.40 & 0.90 & 0.40 & 0.07 & 0.32 \\
\hline & YSM $20+$ yrs & 0.06 & 0.20 & 0.83 & 0.34 & 0.83 & 0.34 & 0.06 & 0.37 \\
\hline & Second Gen. & 0.09 & 0.21 & 0.81 & 0.40 & 0.69 & 0.20 & 0.03 & 0.25 \\
\hline & Total & 0.09 & 0.20 & 0.82 & 0.39 & 0.71 & 0.26 & 0.04 & 0.27 \\
\hline
\end{tabular}




\section{Acknowledgments}

The paper was based on collaboration with Statistics Netherlands. The authors are grateful to Henk-Jan Dirven. They also gratefully acknowledge the comments of the referee.

\section{Endnotes}

1. Extending the present analysis of occupational assimilation, Zorlu [21] uses three alternative measures of occupational attainment, with special emphasis on the interplay between education and occupational attainment. We cannot add an analysis of wages as our data do not include information about wages;

2. We do not want to engage in disputes over terminology or definition of integration versus assimilation, etc. We take our definition as simply reflecting a policy goal;

3. Labour market assimilation of immigrant women has been studied in only a very limited number of studies (see e.g., $[22,23]$ );

4. We have longitudinal data on labour market position, but information on education is not included;

5. In fact, in the US, where change in cohort quality is much debated, most of the change also reflects change in source country composition;

6. More recent studies proposed a family framework to analyse the labour supply of immigrant men and women since labour market decisions of spouses are interrelated. Baker and Benjamin [24] argued that immigrant husbands work less than comparable natives after arrival in Canada, while immigrant wives work more than natives to support their husbands' investment in human capital. With assimilation, employment rates of immigrant husbands and wives will move towards these of native counterparts. Blau et al. [25] apply a similar framework and conclude that the wage rates and work hours of both immigrant men and women are less than for comparable natives upon arrival in the US, but they increase with time to a similar extent. We plan a separate paper using the family framework;

7. We estimate no second generation gap for refugees, for lack of observations;

8. The maximum is calculated as a first-order condition, $\beta_{4}+2 \beta_{5} \mathrm{YSM}=0$, of the assimilation function $\left(\beta_{4} \mathrm{YSM}+\right.$ $\left.\beta_{5} \mathrm{YSM}^{2}\right)$ in model I for men and women, for instance, $18=0.036 /(2 * 0.001)$;

9. The quadratic term does not differ across the immigrant groups. Therefore, a common quadratic term is maintained for all immigrants, interaction only affects the linear part of YSM;

10. Professional and managerial jobs refer to the categories I and II of Goldthorpe's original eleven classes, while unskilled Jobs are captured by IIIb, VIIa, and VIIb;

11. These maximum values reflect the first-order conditions, derived from the assimilation function $\left(\beta_{4} \mathrm{YSM}\right.$ and $\left.\beta_{5} \mathrm{YSM}^{2}\right)$, calculated using the estimated coefficients for YSM and YSM-squared $\left(\beta_{4}\right.$ and $\left.\beta_{5}\right)$ in Tables 6(a) and 6(b), model IV for immigrant men and women. Note that the maximum for refugee men will differ from other groups since the interaction term with YSM for this group is statistically significant.

\section{References}

[1] G. J. Borjas, "Assimilation and changes in cohort quality revisited: what happened to immigrant earnings in the 1980s?" Journal of Labor Economics, vol. 13, no. 2, pp. 201-245, 1995.

[2] B. R. Chiswick, Y. Cohen, and T. Zach, "The labor market status of immigrants: effects of the unemployment rate at arrival and duration of residence," Industrial and Labor Relations Review, vol. 50, no. 2, pp. 289-303, 1997.

[3] G. J. Borjas, "Assimilation, changes in cohort quality, and the earnings of immigrants," Journal of Labor Economics, vol. 3, no. 4, pp. 463-469, 1995.

[4] B. Chiswick, "The effect of Americanization on the earnings of foreign-born men," Journal of Political Economy, vol. 86, no. 5, pp. 897-921, 1978.

[5] R. M. Friedberg, "You can't take it with you? Immigrant assimilation and the portability of human capital," Journal of Labor Economics, vol. 18, no. 2, pp. 221-251, 2000.

[6] C. Amuedo-Dorantes and S. de la Rica, "Labour market assimilation of recent immigrants in Spain," British Journal of Industrial Relations, vol. 45, no. 2, pp. 257-284, 2007.

[7] P. Bevelander and H. S. Nielsen, "Declining employment success of immigrant males in Sweden: observed or unobserved characteristics?" Journal of Population Economics, vol. 14, no. 3, pp. 455-471, 2001.

[8] S. Wheatley Price, "The employment adjustment of male immigrants in England," Journal of Population Economics, vol. 14, no. 1, pp. 193-220, 2001.

[9] A. Zorlu, J. Hartog, A. Sprangers, and H. Nicolaas, "Retourmigratiegedrag van recente immigranten," Economisch Statistische Berichten, vol. 89, no. 4440, pp. 402-404, 2004.

[10] H. O. Duleep and M. C. Regets, "Immigrants and humancapital investment," American Economic Review, vol. 89, no. 2, pp. 186-191, 1999.

[11] J. Hartog and A. Zorlu, "How important is homeland education for refugees economic position in the Netherlands?" Journal of Population Economics, vol. 22, no. 1, pp. 219-246, 2009.

[12] C. M. Schmidt, "Immigrant performance in Germany: labor earnings of ethnic German migrants and foreign guestworkers," Quarterly Review of Economics and Finance, vol. 37, pp. 379-397, 1997.

[13] P.-A. Edin, R. LaLonde, and O. Aslund, "Emigration of immigrants and measures of immigrant assimilation: evidence from Sweden," Swedish Economic Policy Review, vol. 7, pp. 163-204, 2000.

[14] P. Jensen and P. J. Pedersen, "To stay or not to stay? Out-migration of immigrants from Denmark," International Migration, vol. 45, no. 5, pp. 87-113, 2007.

[15] G. E. Bijwaard, "Immigrant migration dynamics model for The Netherlands," Journal of Population Economics, vol. 23, no. 4, pp. 1213-1247, 2010.

[16] G. Bijwaard, C. Schluter, and J. Wahba, "The impact of labour market dynamics on the return-migration of immigrants," Discussion Paper 5722, IZA, Bonn, Germany, 2011. 
[17] A. Constant and D. S. Massey, "Self-selection, earnings, and out-migration: a longitudinal study of immigrants to Germany," Journal of Population Economics, vol. 16, no. 4, pp. 631-653, 2003.

[18] D. O. Rooth and J. Saarela, "Selection in migration and return migration: evidence from micro data," Economics Letters, vol. 94, no. 1, pp. 90-95, 2007.

[19] P. Longva and O. Raaum, "Unemployment and earnings assimilation of immigrants," Labour, vol. 16, no. 3, pp. 469489, 2002.

[20] G. Evans, "Testing the validity of the goldthorpe class schema," European Sociological Review, vol. 8, no. 3, pp. 211-232, 1992.

[21] A. Zorlu, "Occupational adjustment of immigrants," Discussion Paper 6147, IZA, Bonn, Germany, 2011.

[22] A. Adsera and B. R. Chiswick, "Are there gender and country of origin differences in immigrant labor market outcomes across European destinations?" Journal of Population Economics, vol. 20, no. 3, pp. 495-526, 2007.

[23] R. F. Schoeni, "Labor market assimilation of immigrant women," Industrial and Labor Relations Review, vol. 51, no. 3, pp. 483-504, 1998.

[24] M. Baker and D. Benjamin, "The role of the family in immigrants' labor-market activity: an evaluation of alternative explanations," American Economic Review, vol. 87, no. 4, pp. 705-727, 1997.

[25] F. D. Blau, L. M. Kahn, J. Y. Moriarty, and A. P. Souza, “The role of the family in immigrants' labor-market activity: an evaluation of alternative explanations: comment," American Economic Review, vol. 93, no. 1, pp. 429-447, 2003. 


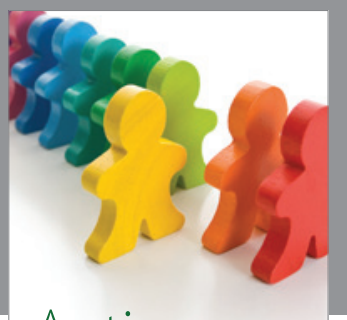

Autism

Research and Treatment
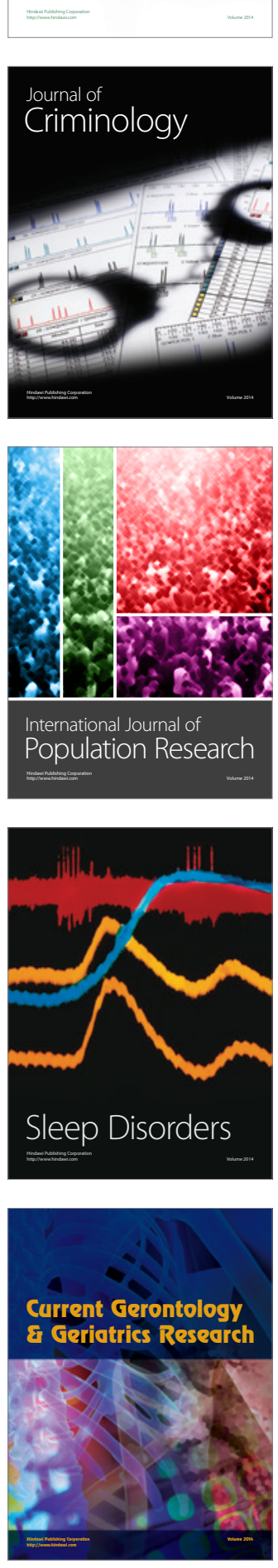
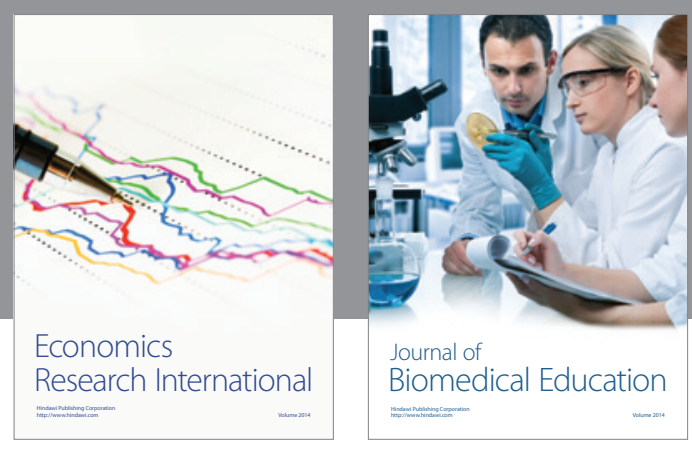

Journal of

Biomedical Education

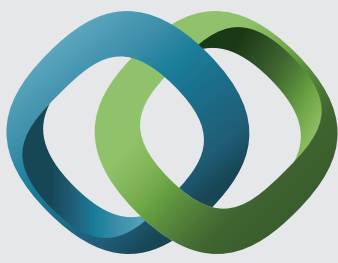

\section{Hindawi}

Submit your manuscripts at

http://www.hindawi.com
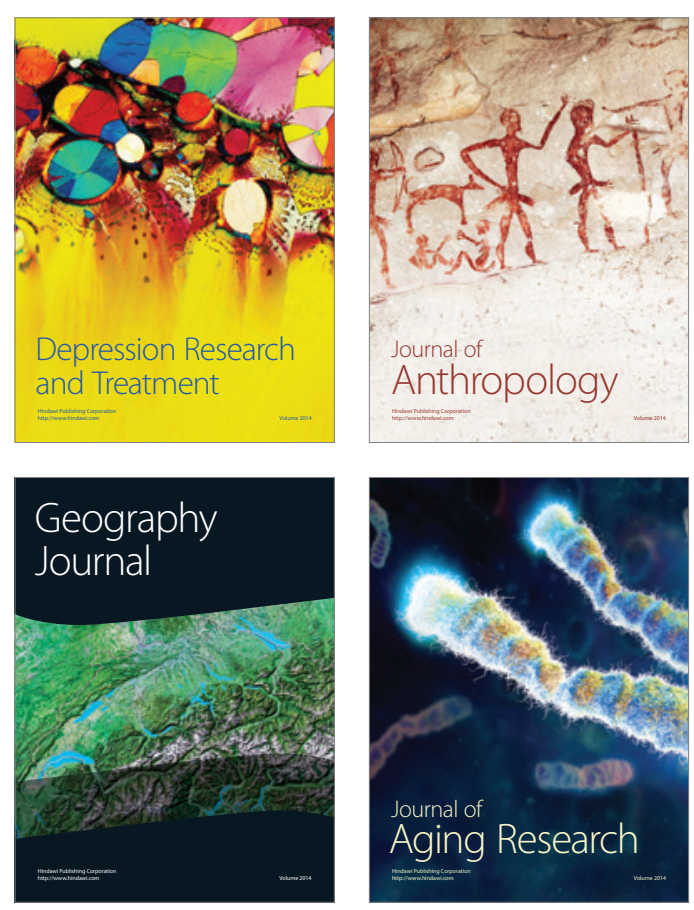

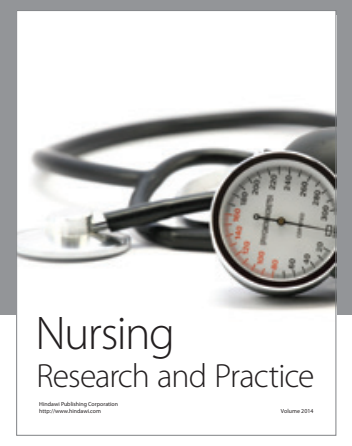

Nursing

Research and Practice

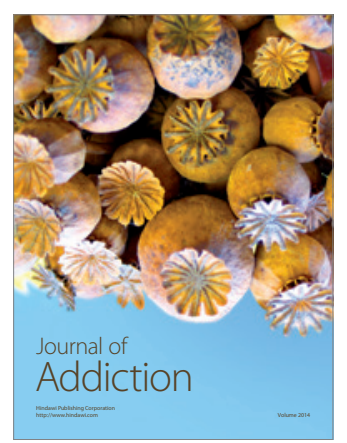

Child Development

Research

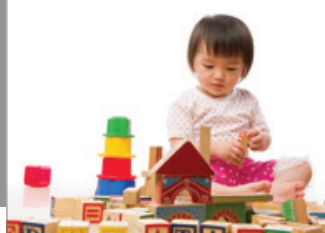

迥
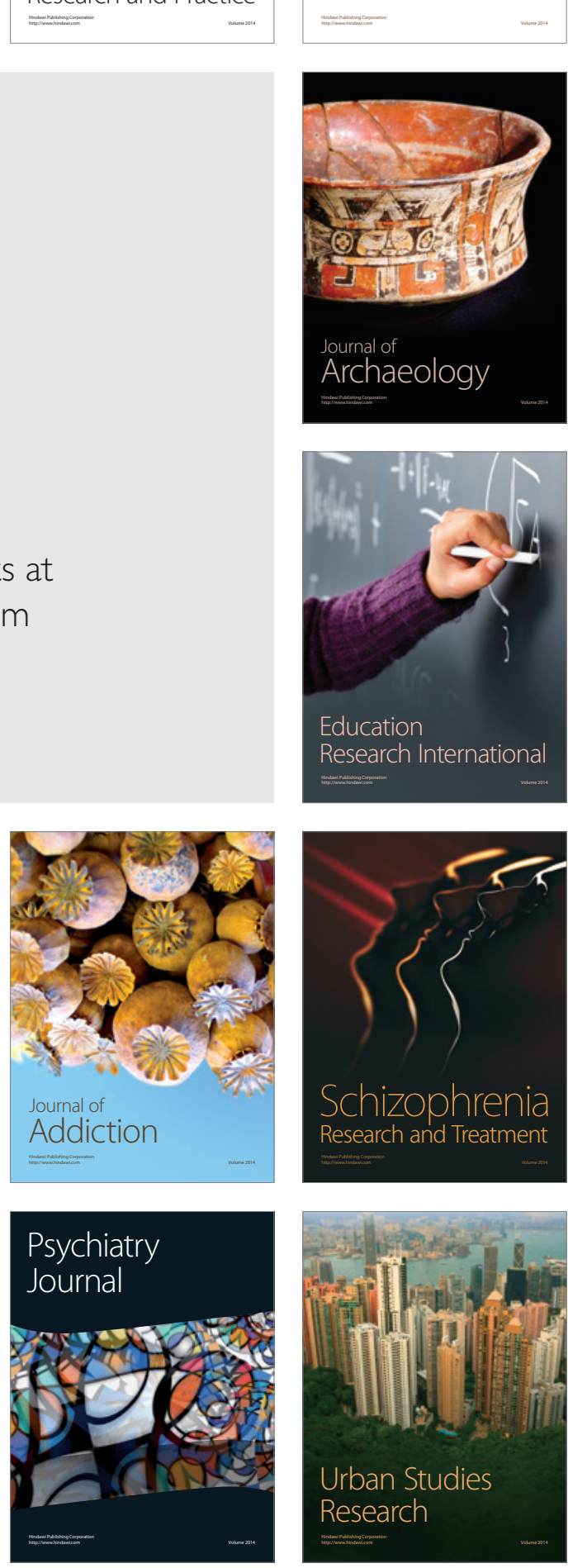